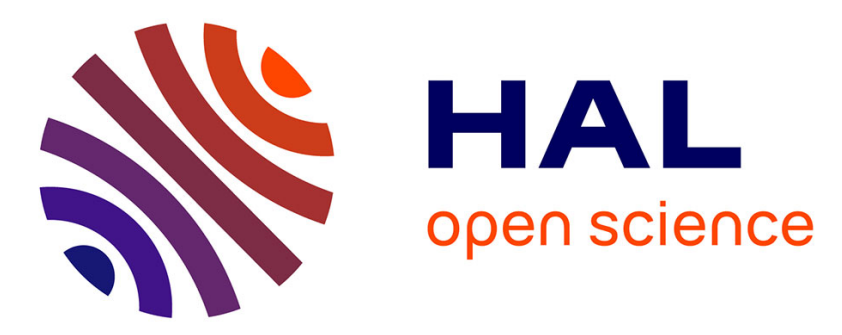

\title{
$\beta$-Phosphorus hyperfine coupling constant in nitroxides: 5. Solvent effect
}

Gérard Audran, Lionel Bosco, Paul Brémond, Teddy Butscher, Jean-Michel

Franconi, Kuanysh Kabitaev, Sylvain Marque, Philippe Mellet, Elodie Parzy, Maurice Santelli, et al.

\section{To cite this version:}

Gérard Audran, Lionel Bosco, Paul Brémond, Teddy Butscher, Jean-Michel Franconi, et al.. $\beta$ Phosphorus hyperfine coupling constant in nitroxides: 5. Solvent effect. RSC Advances, 2016, 6 (7), pp.5653-5670. 10.1039/C5RA23521A . hal-02375539

\section{HAL Id: hal-02375539 \\ https://hal.science/hal-02375539}

Submitted on 22 Nov 2019

HAL is a multi-disciplinary open access archive for the deposit and dissemination of scientific research documents, whether they are published or not. The documents may come from teaching and research institutions in France or abroad, or from public or private research centers.
L'archive ouverte pluridisciplinaire HAL, est destinée au dépôt et à la diffusion de documents scientifiques de niveau recherche, publiés ou non, émanant des établissements d'enseignement et de recherche français ou étrangers, des laboratoires publics ou privés. 


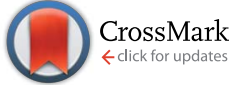

Cite this: RSC Adv., 2016, 6, 5653

\title{
$\beta$-Phosphorus hyperfine coupling constant in nitroxides: 5. Solvent effect $\uparrow$
}

\author{
Gérard Audran, ${ }^{\text {*a }}$ Lionel Bosco, ${ }^{a}$ Paul Brémond, ${ }^{* a}$ Teddy Butscher, ${ }^{a}$ \\ Jean-Michel Franconi, ${ }^{b}$ Kuanysh Kabitaev, ${ }^{a}$ Sylvain R. A. Marque, ${ }^{\text {*ac }}$ Philippe Mellet, ${ }^{\text {bd }}$ \\ Elodie Parzy, ${ }^{\mathrm{b}}$ Maurice Santelli, ${ }^{\mathrm{a}}$ Eric Thiaudière $^{\mathrm{b}}$ and Stéphane Viel ${ }^{\mathrm{ae}}$
}

Recently, we published the titration of water in organic solvents and conversely using this family of nitroxides (Org. Biomol. Chem. 2015 ASAP). In this article, we show that the $a_{\beta, P}$ of persistent cyclic $\beta$ phosphorylated nitroxides decreases with the normalized polarity Reichardt's constant $E_{\mathrm{T}}^{\mathrm{N}}$. Koppel-Palm and Kalmet-Abboud-Taft relationships were applied to get a deeper insight into the effects influencing $a_{N}$ and $a_{\beta, p}$ : polarity/polarizability, hydrogen bond donor property, and structuredness of the cybotactic region.

Received 8th November 2015 Accepted 15th December 2015

DOI: $10.1039 / c 5 r a 23521 a$

www.rsc.org/advances
$2^{*}$ (Fig. 1).t A few years laters, Janzen and coll. ${ }^{\mathbf{1 5}}$ reported a similar effect with $\beta$-phosphorylated cyclic nitroxides (only 3 solvents were investigated). On the other hand, with the persistent ${ }^{16} \quad \mathrm{~N}$-(2-methylpropyl)- $N$-(1-diethylphosphono-2,2dimethylpropyl)- $N$-oxyl radical ( $2^{\prime}$ in Fig. 1$) \mathrm{we}^{\mathbf{1 7}}$ recently showed that $a_{\beta, \mathrm{P}}$ was weakly sensitive to $E_{\mathrm{T}}^{\mathrm{N}}$, with a lot of outliers for alcoholic solvents and water. We also reported ${ }^{18}$ a non linear variation in $a_{\mathrm{P} \beta}$ with $E_{\mathrm{T}}^{\mathrm{N}}$ for the stable nitroxide $2^{\prime \prime}$. Moreover, with $\mathbf{2}^{\prime \prime}$ and $\mathbf{5 c}, \mathbf{t}^{\bullet}$, we highlighted the potential of theses nitroxides to probe the presence of water in organic solvents and conversely. ${ }^{18,19}$ It is well known that $\beta$-phosphorylated pyrrolidinbased nitroxides are persistent ${ }^{\mathbf{1 6 , 2 0}}$ and that the changes in conformation of the 5-membered ring can strikingly modify the values of $a_{\beta, \mathrm{P}}$, as given by the Heller-McConnell relationship ${ }^{21}$ (eqn (1)), by modifying the dihedral angle $\theta$ between the $\mathrm{C}-\mathrm{P}$ bond and the p-shape orbital describing the odd electron localized (Fig. 2) on the nitrogen atom of the nitroxyl moiety (where $\rho_{\mathrm{N}}^{\pi}$ is the electron density on the nitrogen atom of the nitroxyl moiety and proportional to the $a_{\mathrm{N}}$ value, $B_{0} \S$ is the transfer of the spin density through the spin polarization process and $B_{1} \uparrow$ is the transfer of spin density through the hyperconjugation process):

$$
a_{\beta, \mathrm{P}}=B_{0} \rho_{\mathrm{N}}^{\pi}+B_{1} \rho_{\mathrm{N}}^{\pi} \cos ^{2} \theta
$$

${ }^{a}$ Aix-Marseille Université, CNRS-UMR 7273, ICR, Case 541, Avenue Escadrille Normandie-Niemen, 13397 Marseille Cedex 20, France. E-mail: paul.brémond@ univ-amu.fr; sylvain.marque@univ-amu.fr; g.audran@univ-amu.fr

${ }^{b}$ CRMSB, CNRS-UMR-5536, Université Victor Segalen Bordeaux 2, 146 rue Léo Saignat, Case 93, 33076 Bordeaux Cedex, France

${ }^{c} N$. N. Vorozhtsov Novosibirsk Institute of Organic Chemistry SB RAS, Pr. Lavrentjeva 9, 630090 Novosibirsk, Russia

${ }^{d}$ INSERM, 146 rue Léo Saignat, Case 93, 33076 Bordeaux Cedex, France

${ }^{e}$ Institut Universitaire de France, 75000 Paris, France

$\dagger$ Electronic supplementary information (ESI) available: Table 1SI for the solvent parameters. Fig. 1SI for plots $a_{\mathrm{N}} v s . \mu, a_{\mathrm{N}} v s . \varepsilon_{\mathrm{r}}, a_{\beta, \mathrm{P}} v s . \mu$ and $a_{\beta, \mathrm{P}} v s . \varepsilon_{\mathrm{r}}$. Fig. 2SI for plots $a_{\mathrm{N}}$ against $c, V_{\mathrm{X}}(\AA), V_{\mathrm{M}}(\AA), \alpha$ and $\pi^{*}$ and $a_{\beta, \mathrm{P}}$ against $c, V_{\mathrm{X}}(\AA), V_{\mathrm{M}}(\AA), \alpha$ and $\pi^{*}$ (right). Preparation of $4^{*}$ and $5^{*}$. CCDC 985888. For ESI and crystallographic data in CIF or other electronic format see DOI: 10.1039/c5ra23521a
Surprisingly, $\beta$-phosphorylated nitroxides carrying a substituted methylene group at position $\beta$ (Fig. 1) have been

\footnotetext{
$\$$ As far as we know this nitroxide has only been observed through spin-trapping experiments involving the addition of 2-diethoxyphoshorylprop-2-yl radical onto tert-butyl nitroso. Consequently, its preparation on a large scale is expected to be a challenge by conventional procedures.

$\S$ In general, $B_{0}$ is very small and can be neglected. See ref. 10 .

I Values of $B_{1}$ are dependent on the atom or on the function at position $\beta$. See ref. 21 and 10.
} 
<smiles>CC1(C)CC(N)CC(C)(C)N1[O]</smiles>
$1 \cdot$<smiles>CCOC[Pb](C)(OCC)C1(C)CC[C@@](C)(COC(C)=O)N1[O]</smiles>

$4 c$.<smiles>CCOCO[Pb]C1(C)CC[C@@](C)(CN)N1[O]</smiles>

$6 c$.<smiles>CCOC(=O)C(C)(C)N([O])C(C)(C)C</smiles>

2.<smiles>CCOP=C(OCC)C(N([O])C(C)(C)C)C(C)(C)C</smiles>

2'•<smiles>CCOCCOC1(C)C[C@@H](O)CC(C)(C)N1[O]</smiles>

2'<smiles>CCOCC(C)([Po])C1(C)CCC(C)(C)N1[O]</smiles>

$3^{\circ}$

Fig. 1 Nitroxides investigated: $\mathrm{c}$ for the cis isomer and $\mathrm{t}$ for the trans isomer.

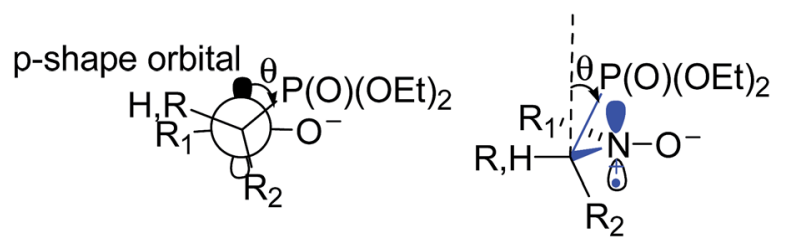

Fig. 2 Hyperconjugation effect describing the origin of the coupling between the nuclear spin of the phosphorus atom and the $\mathrm{p}$-shape orbital on the $\mathrm{N}$ atom of the nitroxyl moiety. Newman projection on the left, dihedral angle $\theta$ (in blue) on the Cram projection on the right.

only little investigated ${ }^{15,22,23}$ and mainly by spin-trapping. ${ }^{24-27}$ Thus, several nitroxides carrying various groups at position $\beta$ were prepared (Fig. 1), aiming both to vary the steric hindrance and to investigate the effect of stereogenic centres at the $\alpha$ positions of the nitroxyl moiety. A few investigations of the effect of a substituent at position 3 or 4 as well as of the effect of the configuration at positions 2,3 , and 4 for 2,5,5-trimethyl-2diethoxyphosphonyl-pyrrolidin- $N$-oxyl radicals on $a_{\mathrm{N}}$ and $a_{\beta, \mathrm{P}}$ have been reported. ${ }^{28,29}$ Indeed, an extensive investigation on the solvent effect in $\beta$-phosphorylated is timely due to their various applications: (i) as products issued from the spintrapping of radicals by $\beta$-phosphorylated nitroxides taking into account that only a little is known on the solvent effect on spin-adducts and often the trapped radicals are rather basics such as $\mathrm{Me}^{\circ}, \mathrm{HO}^{\circ}, \mathrm{HOO}^{\circ}, \ldots$; (ii) as component of alkoxyamines which are currently used as initiator/controller in nitroxide mediated polymerization. ${ }^{30}$ The most efficients are often based on $\beta$-phosphorylated nitroxyl moiety; ${ }^{31}$ (iii) as new spin-label for
Site Directed Spin Labeling (SDSL) for which changes in hcc might provide information on the folding-unfolding process, ${ }^{32}$ and (iv) as spin probe to investigate non-radical enzymatic activity by Overhauser-enhanced Magnetic Resonance Imaging (OMRI) and EPR. ${ }^{33}$

\section{Results}

\section{Preparation of nitroxides $3^{\circ}-7 \mathbf{t}^{*}$}

Nitroxides $3^{\circ}$ (ref. 34 ) and $7 \mathbf{t}^{\circ}$ (ref. 35) were prepared as reported in the literature. Aziridine 3 was prepared as recently reported from commercially available 6-methylhex-5-en-2-one 1 (Scheme 1). ${ }^{35}$ Aziridine 3 was obtained as two diastereoisomers cis (3c)

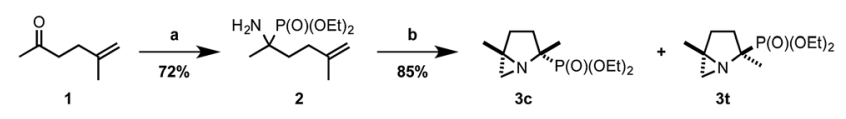

Scheme 1 Preparation of the aziridine key-intermediate 3 . Reagents and conditions: (a) $\mathrm{NH}_{3}, \mathrm{HP}(\mathrm{O})(\mathrm{OEt})_{2}, 24$ h, r.t.; (b) $\mathrm{I}_{2}, \mathrm{NaHCO}_{3}, 1,2-$ dichloroethane, $\mathrm{H}_{2} \mathrm{O}, 2 \mathrm{~h}$, reflux.

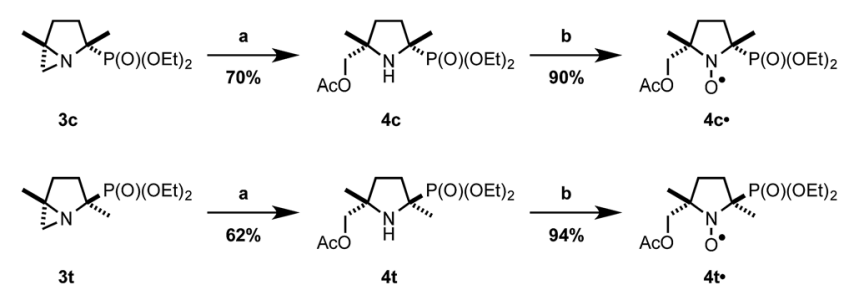

Scheme 2 Synthesis of $4 c, t^{*}$. Reagents and conditions: (a) $\mathrm{AcOH}, 24 \mathrm{~h}$, r.t.; (b) $m$-CPBA, $\mathrm{CH}_{2} \mathrm{Cl}_{2}, 2-4$ h, r.t. 


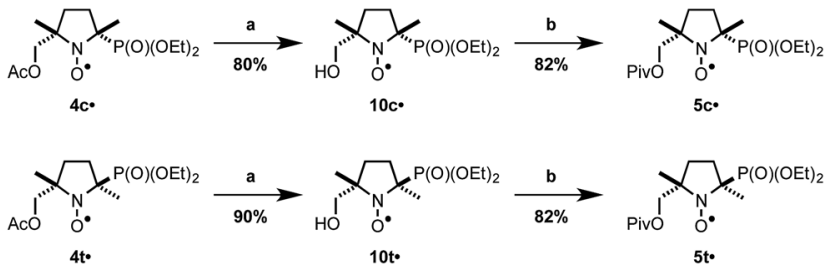

Scheme 3 Synthesis of $5 c, t^{*}$. Reagents and conditions: (a) $\mathrm{K}_{2} \mathrm{CO}_{3}$, $\mathrm{MeOH}, 24$ h, r.t.; (b) $\mathrm{PivCl}, \mathrm{Et}_{3} \mathrm{~N}$, DMAP, $\mathrm{CH}_{2} \mathrm{Cl}_{2}, 24$ h, r.t.

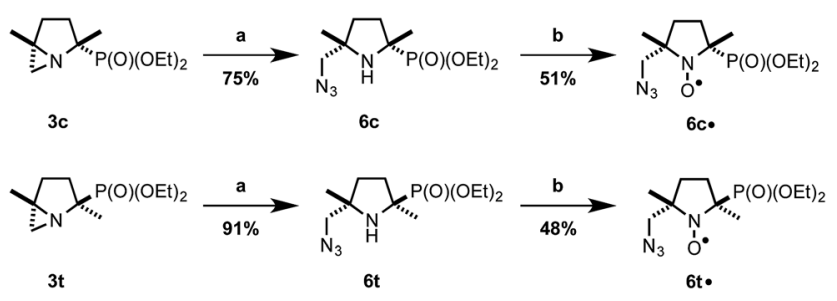

Scheme 4 Synthesis of $6 c, t^{\circ}$. Reagents and conditions: (a) $\mathrm{NaN}_{3}$, $\mathrm{NH}_{4} \mathrm{Cl}, \mathrm{CH}_{3} \mathrm{CN}, 3$ h, reflux; (b) $m-\mathrm{CPBA}, \mathrm{CH}_{2} \mathrm{Cl}_{2}$, r.t., 1 h.

and trans (3t), which were separated by column chromatography on silica gel. Their relative configuration was determined by NMR and X-ray studies (vide infra).

The nucleophilic addition of acetic acid onto $\mathbf{3 c}, \mathbf{t}$ afforded adducts $4 \mathbf{c}, \mathbf{t}$ in $62-70 \%$. They were subsequently oxidized by $m$-CPBA (90-94\% yield) into nitroxides $\mathbf{4} \mathbf{c}^{\circ}$ and $\mathbf{4 t}^{\circ}$ (Scheme 2).

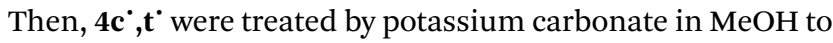
afford $10 \mathbf{c}^{\circ}, \mathbf{t}^{*}$ (80-90\% yield), which were then esterified with pivaloyl chloride ( $82 \%$ yield) to afford $\mathbf{5} \mathbf{c}^{\circ}$ and $\mathbf{5 t ^ { \circ }}$, respectively (Scheme 3).

The nucleophilic addition of sodium azide onto $3 \mathbf{c}$ and $\mathbf{3 t}$ afforded $\mathbf{6 c}$ and $\mathbf{6 t}$, respectively, which were subsequently oxidized into nitroxides $6 \mathbf{c}^{\circ}$ and $\mathbf{6 \mathbf { t } ^ { \circ }}$ (Scheme 4).

\section{NMR, EPR and X-ray analyses}

Once aziridines $\mathbf{3 c}$ and $\mathbf{3 t}$ were separated, $\mathbf{6 c}$ (minor diastereoisomer) and 6t (major diastereoisomer) were prepared by a univocal route (Scheme 4). Their relative configuration was determined using NOESY experiments. The Overhauser effect was observed between the two methyl groups for $\mathbf{6 c}$ whereas it was not observed for 6t (Fig. 3). || The relative configuration was definitely ascribed by the X-ray analysis of $\mathbf{1 0 t}^{*}$ (Fig. 4), ${ }^{* *}$ which nicely confirmed the NOESY experiment, as $10 \mathbf{t}^{\circ}$ was also prepared through a univocal route from 3t (Scheme 2 and 3). Consequently, the stereochemistry of each stereocenter in $4^{\bullet}-6^{*}$ (Fig. 1) was ascertained from these two molecules.

|| In Fig. 3, for (a), selective irradiation of these $\mathrm{CH}_{2}$ signals gave rise to informative NOE cross-peaks (evidenced by green and red boxes) which are due to $\mathrm{CH}_{3}$ groups as illustrated in (b). This confirmed the trans configuration of the 5-membered ring. In contrast, irradiation of the same $\mathrm{CH}_{2}$ protons in (c) afforded only rise to one NOE cross-peak with the neighboring $\mathrm{CH}_{3}$ group, in agreement with the expected cis configuration.

** CCDC: 985888 .† (a)
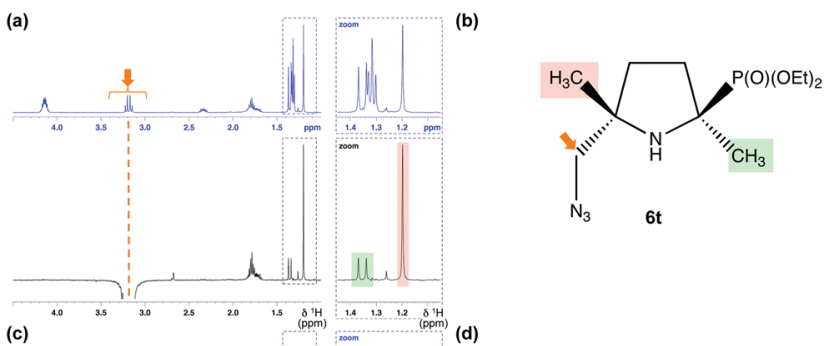

(c)
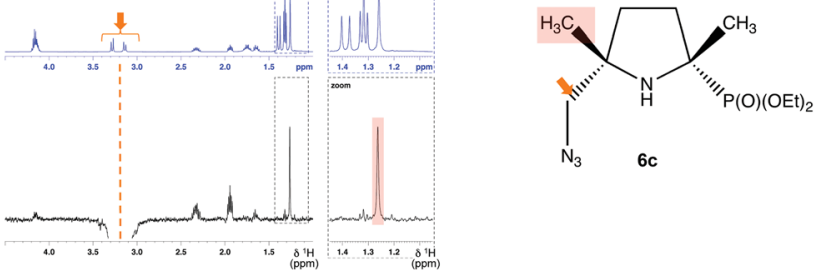

Fig. $3500.13 \mathrm{MHz}$ one-dimensional (1D) ${ }^{1} \mathrm{H}$ NMR and ${ }^{1} \mathrm{H}$ selective NOE NMR spectra (blue and black traces, respectively) recorded at $300 \mathrm{~K}$ in $\mathrm{CDCl}_{3}$ solutions of (a) $6 \mathrm{t}$ and (c) $6 \mathrm{c}$, the molecular structures of which are reported in (b) and (d), respectively. The orange arrows shown in (a) and (c) indicate the signals that were selectively irradiated in the $1 \mathrm{D}^{1} \mathrm{H}$ NOE NMR experiments and that correspond to the $\mathrm{CH}_{2}$ protons (AB spin system) of the pendant $\mathrm{CH}_{2} \mathrm{~N}_{3}$ moiety. Dotted zones in right side in (a) and (c) correspond to a zoom from the dotted zone on the main spectrum. The green and pink colored zones in (a)-(d) highlight the zones sensitive to the irradiation of the $\mathrm{CH}_{2} \mathrm{~N}_{3}$ group.

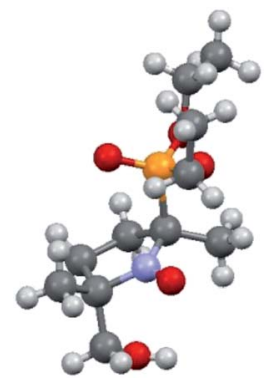

Fig. 4 X-ray analysis of $10 t^{*}$.

All nitroxides displayed in Fig. 1 exhibit the expected 6-line EPR signal due to the coupling between the nuclear spins of the nitrogen atom $\left(I_{N}=1\right)$ and phosphorus atom $\left(I_{P}=1 / 2\right)$ and the odd electron on the nitroxyl moiety. Signals were recorded in more than 40 solvents. Nitrogen and $\beta$-phosphorus hyperfine coupling constants (hcc) $a_{\mathrm{N}}$ and $a_{\beta, \mathrm{P}}$ for $\mathbf{1}^{\circ}-\mathbf{7 t}^{\circ}$ are collected in Table 1 excepted for $2^{\prime}$ and $2^{\prime \prime}$.

\section{Non-specific properties of the solvent}

Among the non-specific solvent properties available, - dipolar moment $\mu$, relative permittivity constant $\varepsilon_{\mathrm{r}}$, viscosity $\eta$ and refractive index $n$ - only $\mu$ and $\varepsilon_{\mathrm{r}}$ were tested, as they were related to the polarity of the solvent (Table $1 \mathrm{SI} \dagger$ ). As already reported for $\mathbf{1}^{\cdot{ }^{17}}$ scattered plots were observed with $\mu$ and $\varepsilon_{\mathrm{r}}$, 


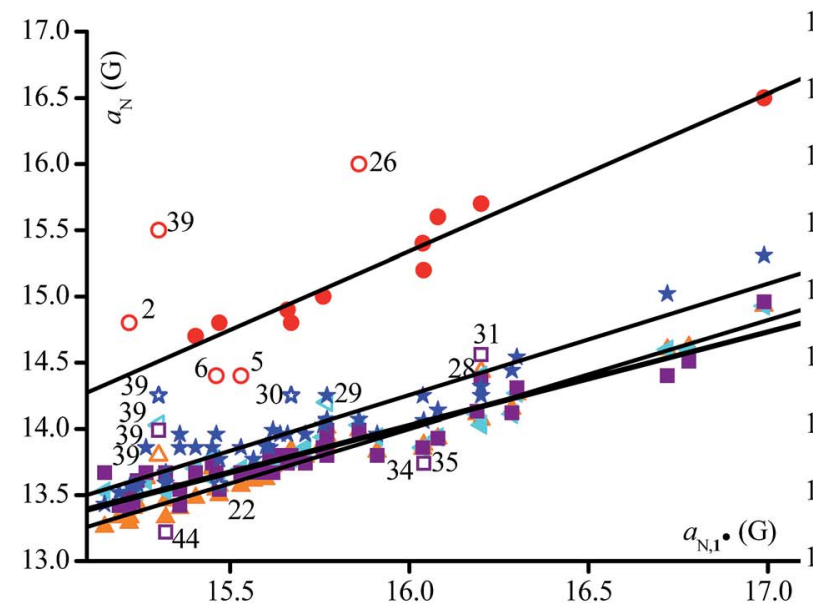

(a)

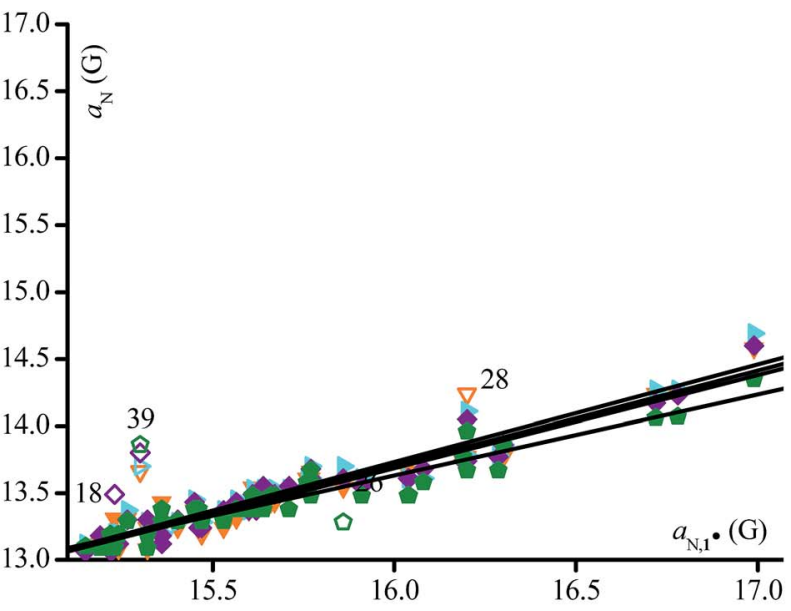

(b)

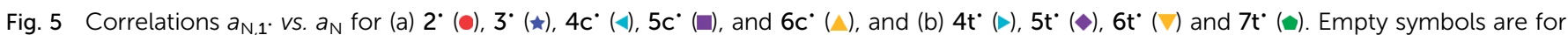
outliers.

like with $a_{\mathrm{N}}$ and $a_{\beta, \mathrm{P}}$ for $\mathbf{3}^{\cdot}-\mathbf{7 t}^{\bullet}$ (Fig. 1SI $\dagger$ ). $\dagger^{\dagger} \dagger$ Nevertheless, two trends were observed: $a_{\mathrm{N}}$ increased with increasing $\mu$ and $\varepsilon_{\mathrm{r}}$, i.e., with increasing polarity, and $a_{\beta, \mathrm{P}}$ decreased with increasing $\mu$ and $\varepsilon_{\mathrm{r}}$.

\section{Correlation of $a_{\mathrm{N}}$ and $\boldsymbol{a}_{\beta, \mathrm{P}}$ with benchmark hecs}

As $1^{\circ}$ was the nitroxide used in the first extensive study of solvent effects, ${ }^{9}$ its $a_{\mathrm{N}}$ values are considered as benchmark values to investigate the solvent effect. ${ }^{1,2}$ In $1976,2^{\circ}$ was used in the first extensive solvent study (18 solvents) for nitroxides carrying a phosphorus atom at position $\beta .^{\mathbf{1 2}}$

The plots of $a_{\mathrm{N}}$ for $3^{\circ}-7 \mathbf{t}^{\cdot}$ against $a_{\mathrm{N}}$ for $\mathbf{1}^{\cdot}$ (benchmark molecule, eqn (2)) show that $\mathbf{3}^{\cdot} \mathbf{-} \mathbf{7} \mathbf{t}^{\bullet}$ experience a weaker solvation effect on their nitroxyl moieties than $\mathbf{1}^{\circ}$ does. Thus, $4 \mathbf{c}, \mathbf{t}^{\bullet}$, $\mathbf{5 c}, \mathbf{t}^{*}$, and $\mathbf{6 t ^ { * }}$ experience a similar solvent effect (same slopes $\alpha_{1}$ in eqn ( $2 \mathrm{c}-\mathrm{f}$ and $\mathrm{h}$ ), Table $2 \mathrm{SI}$ ) although weaker than for $3^{\circ}$ and $\mathbf{6 c}^{\mathbf{*}}$, and stronger than for $\mathbf{7 \mathbf { t } ^ { \circ }}$. TEG (39) is an outlier for all nitroxides, likely due to its high viscosity affording a peculiar solvation of the nitroxyl moiety. At this time, there is no rationale to take into account the other outliers.

$$
a_{\mathrm{N}}=y_{0}+\alpha_{1} a_{\mathrm{N}, \mathbf{1}}
$$

The plots $a_{\mathrm{N}}$ of $4^{-}-7 \mathbf{t}^{\bullet}$ against $a_{\mathrm{N}}$ of $3^{\circ}$, selected as the reference for the nitroxides carrying a phosphoryl group (eqn (3)), show that the nitroxyl moieties of $\mathbf{4 c}, \mathbf{t}^{\circ}, \mathbf{5 c}, \mathbf{t}^{\circ}$ and $\mathbf{6 \mathbf { t } ^ { \circ }}$ experienced the same solvation effect as $3^{\circ}$ did (Fig. 6 and Table $3 S{ }^{\dagger} \dagger$ ). On the other hand, $\mathbf{6} \mathbf{c}^{\circ}$ experienced a stronger solvation effect whereas $7 \mathbf{t}^{\bullet}$ experienced a weaker solvation effect. There is no rationale to take into account solvents $\mathrm{F}(28), \mathrm{i}-\mathrm{Pr}_{2} \mathrm{NH}(45), n-\mathrm{Bu}_{2} \mathrm{O}$ (19), and DMF (30) as outliers. Interestingly, for most nitroxides, EG (38) and TEG (39) are outliers, likely due to their high viscosity. For $5 \mathbf{c}^{\cdot}, \mathrm{MeOH}(31)$ and $\mathrm{Et}_{3} \mathrm{~N}(44)$ are also outliers.

$\dagger$ All figures were very similar.

$$
a_{\mathrm{N}}=y_{0}+\alpha_{2} a_{\mathrm{N}, 3}
$$

The plots $a_{\mathrm{N}, \mathbf{1}} \cdot v s . a_{\beta, \mathrm{P}}$ and $a_{\mathrm{N}, 3} \cdot v s . a_{\beta, \mathrm{P}}$ exhibit a decrease in $a_{\beta, \mathrm{P}}$ with increasing $a_{\mathrm{N}}$ values, in sharp contrast to the expectations from eqn (1) (Fig. 7). \$t However, a broad scattering was observed whatever the reference used, implying that the solvation of the nitroxyl moiety has a different impact depending on the nitroxide, as exemplified with $\mathbf{6 t}^{\circ}$ (Fig. 7).

Thus, $3^{\cdot}$ was selected as reference as it is the first 5 -membered ring of this series, i.e. 3 methyl and one diethoxyphosphoryl group at position $\beta$. Good correlations were observed for $4 \mathbf{c}^{\circ}-\mathbf{6} \mathbf{c}^{\circ}$ (eqn (4), Table 4 SI, $\dagger$ Fig. 8) and $4 \mathbf{t}^{\circ}-7 \mathbf{t}^{\circ}$ (eqn (5), Table 5SI, $\dagger$ Fig. 8) with a few outliers. That is, mainly

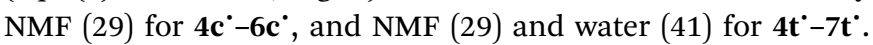
Interestingly, $\mathbf{3}^{\circ}$ and $\mathbf{4} \mathbf{c}^{\circ}-\mathbf{6} \mathbf{c}^{\circ}$ experienced the same solvent effect, as shown by the very close values of their slopes (Table 4SI $\dagger$ ). On the other hand, a stronger effect (Table 5SI $\dagger$ ) was observed for $\mathbf{4 t}^{\mathbf{}} \mathbf{- 6} \mathbf{t}^{\mathbf{*}}$, implying more important conformational changes, in contrast to $7 \mathbf{t}^{\circ}$.

$$
\begin{gathered}
a_{\beta, \mathrm{P}, \mathbf{c}}=y_{0}+\alpha_{3} a_{\beta, \mathrm{P}, \mathbf{3}} \cdot \\
a_{\beta, \mathrm{P}, \mathbf{t}}=y_{0}+\alpha_{4} a_{\beta, \mathrm{P}, \mathbf{3}} . \\
a_{\beta, \mathrm{P}, \mathbf{t}}=y_{0}+\alpha_{5} a_{\beta, \mathrm{P}, \mathbf{c}} \cdot \\
a_{\mathrm{N}}=y_{0}+\alpha_{7} E_{\mathrm{T}}^{\mathrm{N}} \\
a_{\beta, \mathrm{P}}=y_{0}+\alpha_{8} E_{\mathrm{T}}^{\mathrm{N}}
\end{gathered}
$$

Interestingly, when the $a_{\beta, \mathrm{P}}$ of the diastereoisomers are plotted against each other, very good correlations are observed (Fig. 8c). They show that the conformational changes are 


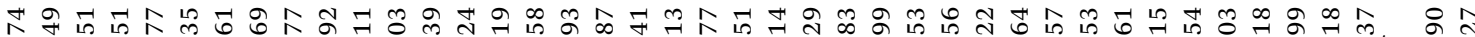

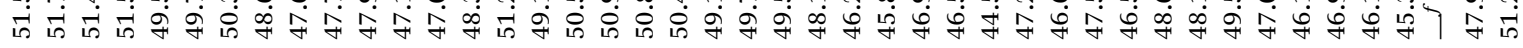
웅 궁

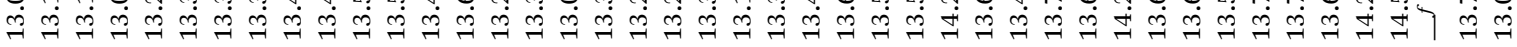

$\dot{0}$

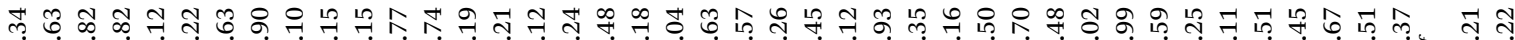

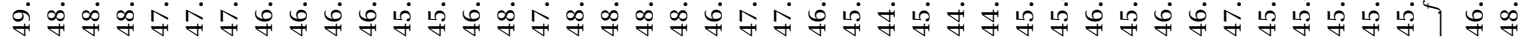

శై

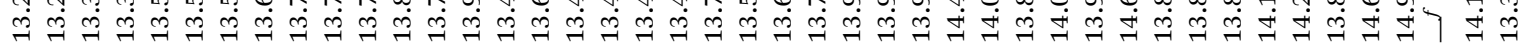

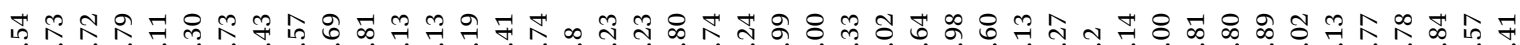

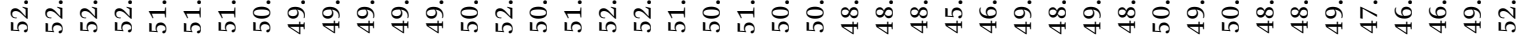

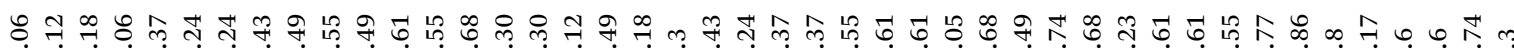

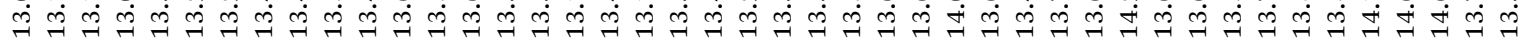

웅

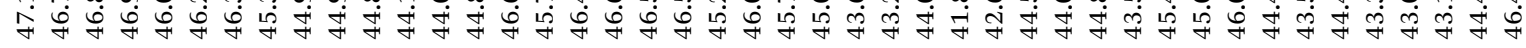

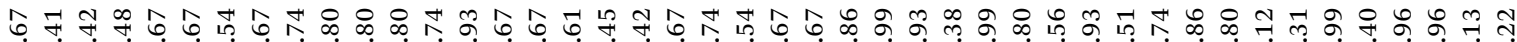

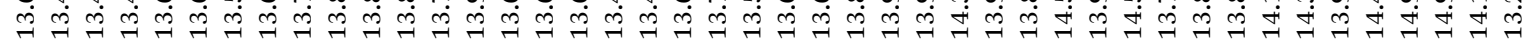

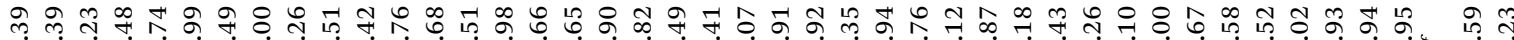

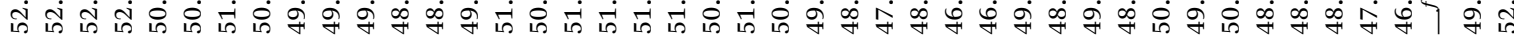

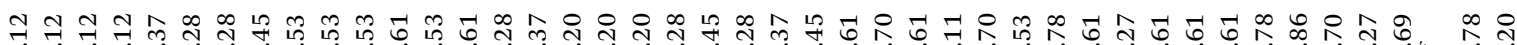

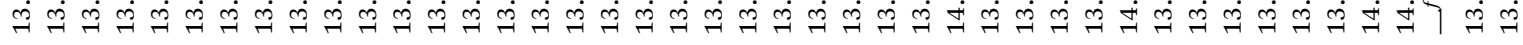

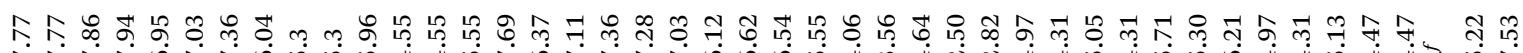

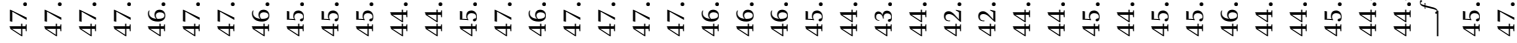

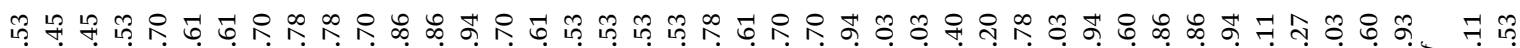

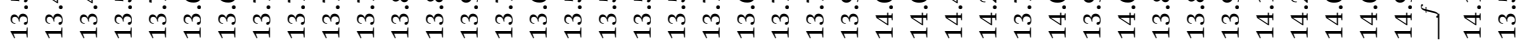

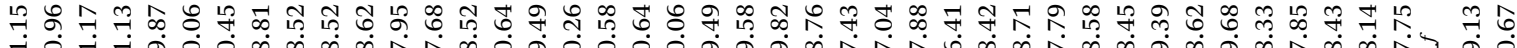

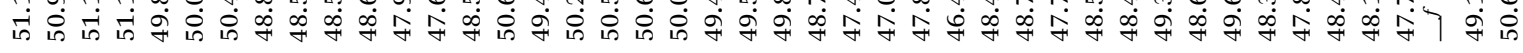

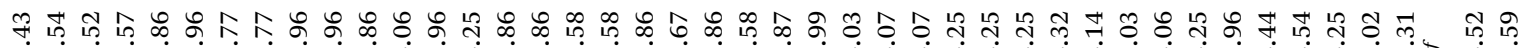
岛

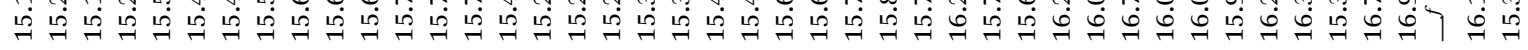




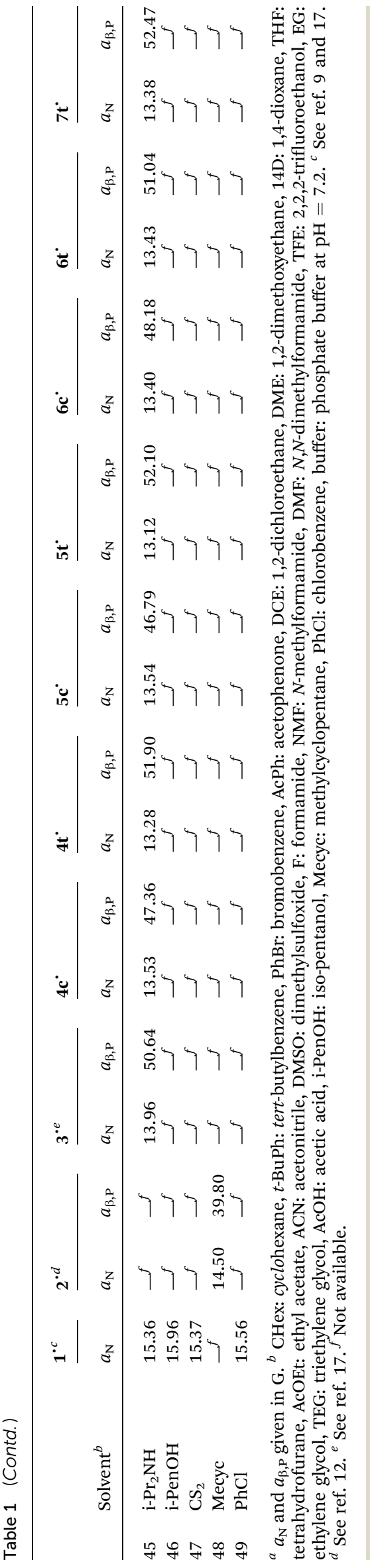

different from one diastereoisomer to the other (Table 6SI $\dagger$ ) and always afford a $\theta$ value smaller for the trans configuration than for the cis configuration (vide infra). Noteworthily, only a few outliers were observed, i.e., water (41) for $\mathbf{4}^{*}$, benzene (5) for $5^{*}$, formamide (28) for $6^{*}$.

\section{Solvent effect on $a_{\mathrm{N}}$ and $a_{\mathrm{P} \beta}$ in the cybotactic region}

The cybotactic effect of 45 solvents was investigated for each diastereoisomer separately (Table 1). Correlations of $a_{\mathrm{N}}$ and $a_{\mathrm{P} \beta}$ with non-specific solvent parameters such as the dipole moment $\mu$, the relative constant $\varepsilon_{\mathrm{r}}$, and the refractive index $n$ afforded only scattered plots (see ESI $\dagger$ ). Thus, we investigated the specific solvent parameters related to the Hydrogen Bonding Donating (HBD) property $\alpha, \S \S$ the intrinsic volume $V_{\mathrm{X}}$, the cohesive pressure $c$ (square of the Hildebrand solubility parameter $\delta$ ), the molar volume $V_{\mathrm{M}}$, and the normalized Reichardt polarity solvent parameter $E_{\mathrm{T}}^{\mathrm{N}}$ (all these values are reported in Table 1SI $\dagger$ ). Except for $E_{\mathrm{T}}^{\mathrm{N}}$, all parameters afforded scattered plots, both for $a_{\mathrm{N}}$ and $a_{\mathrm{P} \beta}$. Although scattering seems weak in Fig. 9 and 10 for the plots $E_{\mathrm{T}}^{\mathrm{N}} v s . a_{\mathrm{N}}$ or $a_{\beta, \mathrm{P}}$, respectively, it is still strong for $3^{-}-7 \mathbf{t}^{\bullet}\left(R^{2}<0.90\right.$, eqn $(7 \mathrm{c}-\mathrm{j})$ and $(8 \mathrm{~b}-\mathrm{i})$ in Tables 2 and 3, respectively), even after several outliers have been removed.

Amazingly, two correlations are possible for $3^{\circ}$ and $7 \mathbf{t}^{\circ}$ (eqn (8b, c and j, k), respectively, in Table 3) affording good statistical outputs and different parameters, provided at least 10 solvents are removed! This highlights very nicely that $E_{\mathrm{T}}^{\mathrm{N}}$ is not a suitable parameter to describe the solvent effect on $a_{\beta, \mathrm{P}}$.

\section{Dihedral angle changes}

As mentioned in the introduction, the coupling with the atom at position $\beta$ is given by the Heller-McConnell relationship (eqn (1)) which in turn depends on the spin density on the nitrogen atom $\rho_{\mathrm{N}}^{\pi}$, straightforwardly related to $a_{\mathrm{N}}$, and to the dihedral angle $\theta$ between the bond of the atom at position $\beta$ and the $\mathrm{p}$-shape orbital on the $\mathrm{N}$ atom. Years ago, ${ }^{28,29}$ it was shown that $\rho_{\mathrm{N}}^{\pi} B_{1}$ in an apolar solvent such as $n$ hexane is around $59 \mathrm{G}$ for the diethoxyphosphoryl group at position $\beta$ of the nitroxyl moiety. Then, using eqn (1) it was possible to determine $\theta_{1}$ for each nitroxide in the solvent exhibiting the largest $a_{\beta, \mathrm{P}}$ value. Thus, applying eqn (9), $\theta$ values were determined for each nitroxide in each solvent and displayed in Fig. 11. The main features - solvents, lowest and highest values of $a_{\mathrm{N}}, a_{\beta, \mathrm{P}}$ and $\theta$, and its variation $\Delta \theta$ - are stored in Table 4.

$$
\frac{a_{\mathrm{P}, 1}}{a_{\mathrm{P}, n}}=\frac{a_{\mathrm{N}, 1}}{a_{\mathrm{N}, n}} \frac{\cos ^{2} \theta_{1}}{\cos ^{2} \theta_{n}}
$$

Interestingly (Table 4), a difference in $a_{\beta, \mathrm{P}}$ of $c a .1 \mathrm{G}$ between $\mathbf{5 t}^{\circ}$ and $\mathbf{6 t}^{\circ}$ is accounted for by a difference of $2^{\circ}$ in $\theta$. The largest values of $a_{\beta, \mathrm{P}}$ are reported in solvents with $E_{\mathrm{T}}^{\mathrm{N}}$ lower than 0.01 . The largest value is not always ascribed to the same solvent.

$\S \S$ The hydrogen bonding acceptor HBA property $\beta$ was not considered, as the investigated nitroxides did not exhibit "acidic" proton. 


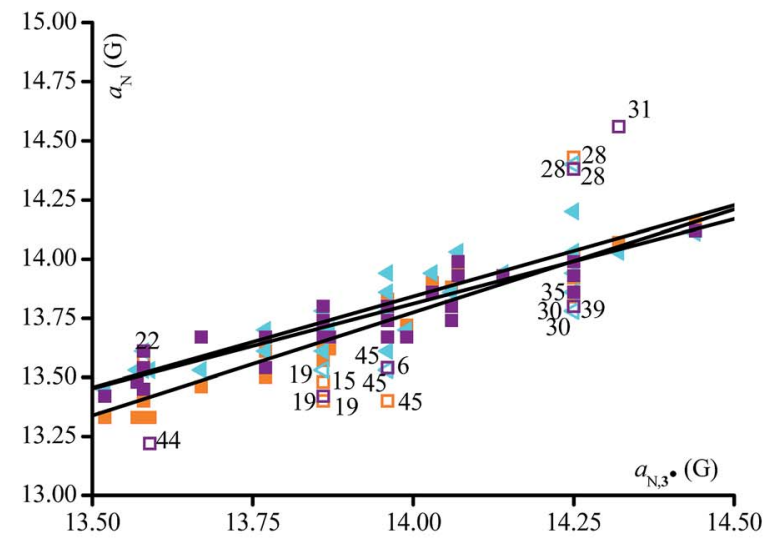

(a)

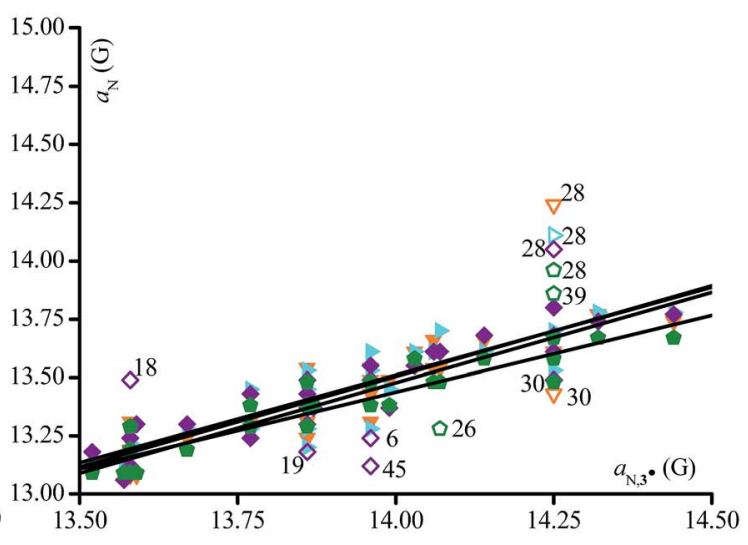

(b)

Fig. 6 Correlations $a_{N, 3^{*}} v s$. $a_{N}$ for $(a) 4 c^{\circ}(\triangleleft), 5 c^{\circ}(\square)$, and $6 c^{\circ}(\Delta)$, and (b) $4 t^{*}(\bullet), 5 t^{*}(\diamond), 6 t^{*}(\nabla)$ and $7 t^{*}(\Delta)$. Empty symbols are for outliers.
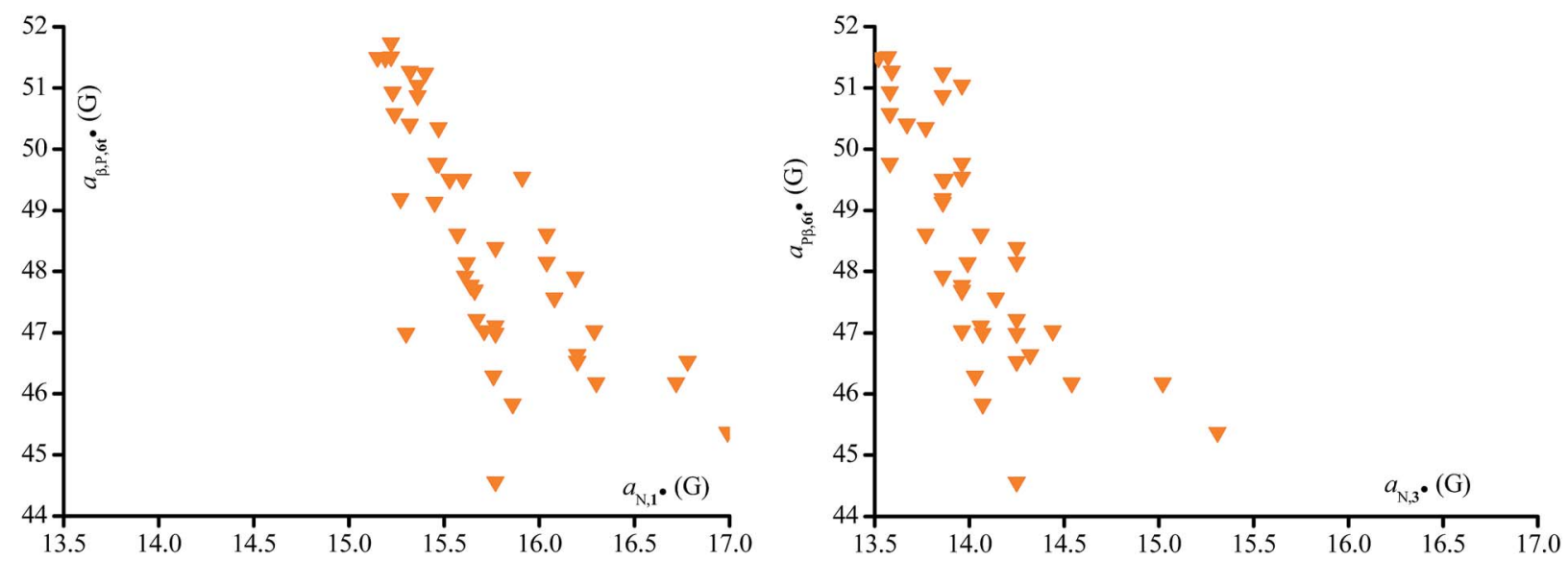

Fig. 7 Plots $a_{N, 1} \cdot v s . a_{\beta, P, 6 t^{*}}\left(\right.$ left) and $a_{N, 3} \cdot v s . a_{\beta, P, 6 t^{*}}$ (right), as examples.

However, the difference in $a_{\mathrm{P} \beta}$ between solvents is negligible, i.e., less than 0.3 G. Except for $\mathbf{2}^{\circ}$ and $\mathbf{6 t}^{\circ}, a_{\beta, P \min }$ values are reported in formamide whereas the corresponding $\theta_{\max }$ are given in water, except for $\mathbf{4 c ^ { \circ }}$ and $7 \mathbf{t}^{\circ}$. This denotes solvent effects strongly dependent on the structure of the nitroxide. $\Delta \theta$ varies from $9^{\circ}$ to $14^{\circ}$, whatever the difference in $a_{\beta, \text { Pmax }}$ and $a_{\beta, \text { Pmin }}$ for $3^{\circ}-7 \mathbf{t}^{\bullet}$ (Table 4). This denotes very similar conformations and conformational changes for both cis and trans series. Amazingly, the highest values observed for $\theta_{\max }$ for $3^{\circ}-7 \mathbf{t}^{\circ}$ are similar to the lowest value observed for $\theta$ for $2^{\circ}$, meaning that the bond rotations in $\mathbf{3}^{\circ}-\mathbf{7 \mathbf { t } ^ { \circ }}$ are restricted.

\section{Multiparameter correlations}

As several outliers and significant scatterings were observed when mono-parameter correlations were performed, multiparameter relationships based on the Koppel-Palm (KP) and the Kalmet-Abboud-Taft (KAT) relationships (eqn (10) and (11), and eqn (15) and (16), respectively) 9 were tested with $a_{\mathrm{N}}$ and

ฯ 9 These two relationships are often used to investigate the solvent effects. See ref. 13.
$a_{\mathrm{P} \beta}$. The KP relationship is a 6-parameter relationship combining two non-specific parameters - the polarizability parameter based on the refractive index $n$, given by the LorenzLorentz function (eqn (12)), and the polarity parameter, based on the relative permittivity $\varepsilon_{\mathrm{r}}$, given by the Kirkwood function (eqn (13)) - and four solvent specific parameters - the solvent basicity/nucleophily parameter $B$, the solvent acidity/ electrophily parameter $E$, the Hildebrand's solubility parameter $\delta_{\mathrm{H}}$, and the molar volume $V_{\mathrm{M}}$ of the solvent. The values of $E$ were determined using eqn (14) based on the Kirkwood (eqn (13)) and Lorenz-Lorentz (eqn (12)) functions and the DimrothReichardt polarity parameter $E_{\mathrm{T}, 30}$.

$$
\begin{aligned}
\log a_{\mathrm{N}}= & \log a_{\mathrm{N}, 0}+a_{1} f\left(n^{2}\right)+a_{2} f\left(\varepsilon_{\mathrm{r}}\right)+a_{3} B+a_{4} E+a_{5} \delta_{\mathrm{H}}^{2} \\
& +a_{6} V_{\mathrm{M}} \\
\log a_{\beta, \mathrm{P}}= & \log a_{\beta, \mathrm{P} 0}+b_{1} f\left(n^{2}\right)+b_{2} f\left(\varepsilon_{\mathrm{r}}\right)+b_{3} B+b_{4} E+b_{5} \delta_{\mathrm{H}}^{2} \\
& +b_{6} V_{\mathrm{M}} \\
& f\left(n^{2}\right)=\frac{\left(n^{2}-1\right)}{\left(n^{2}+2\right)}
\end{aligned}
$$




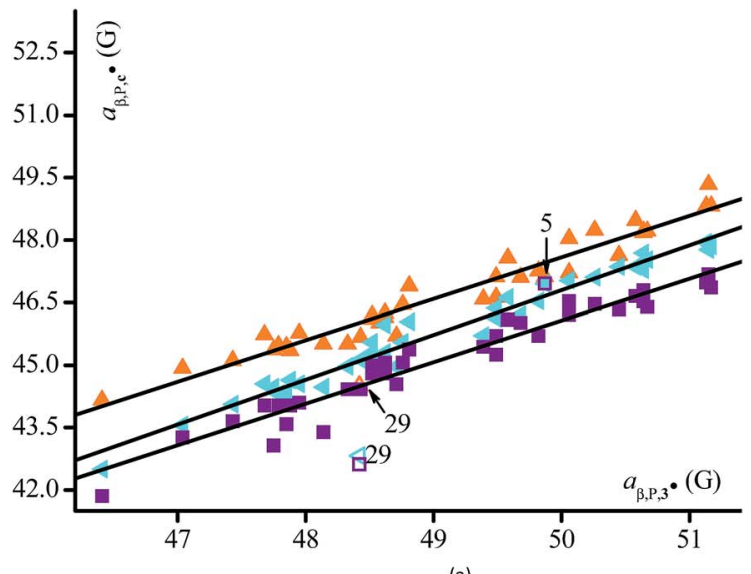

(a)

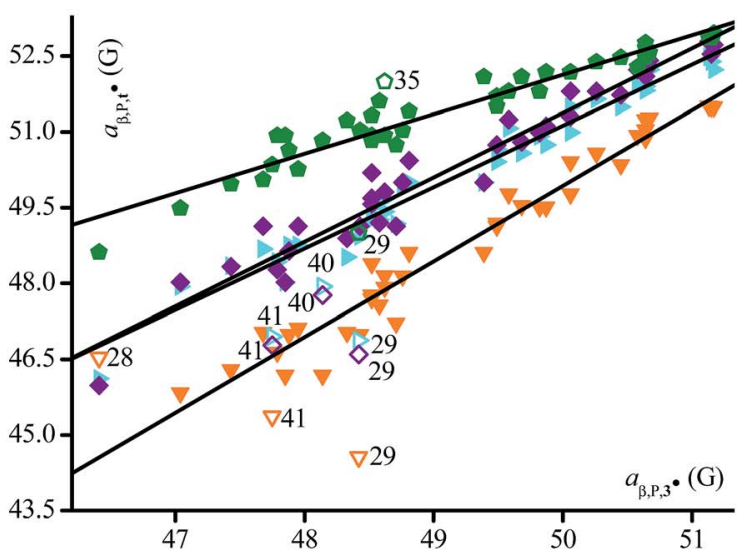

(b)

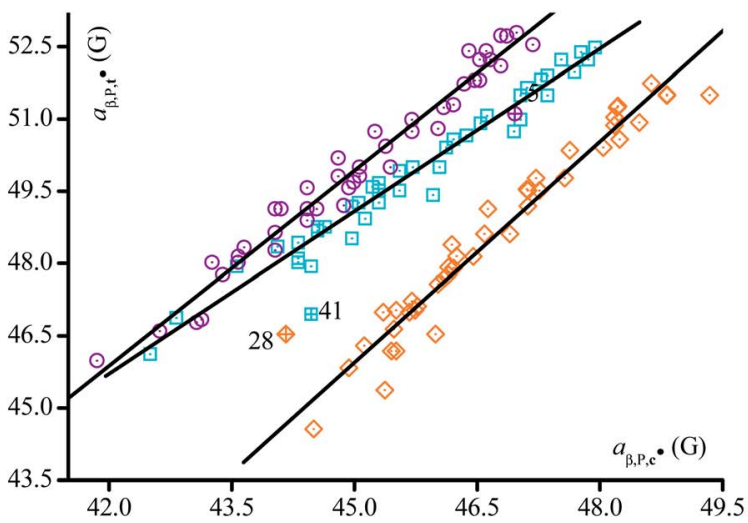

(c)

Fig. 8 (a) Plots $a_{\beta, P, 3^{*}} v s$. $a_{\beta, P}$ for $4 c^{*}(\triangleleft), 5 c^{*}(\square)$, and $6 c^{*}(\Delta)$. (b) Plots $a_{\beta, P, 3} \cdot v s$. $a_{\beta, P}$ for $4 t^{*}(\diamond), 5 t^{*}(\triangleleft), 6 t^{*}(\nabla)$, and $7 t^{*}(\bullet)$. (c) Plots $a_{\beta, P, c^{*}} v s$. $a_{\beta, P, t^{*}}$ for 4 $(\sqsubset), 5(\odot)$, and $6(\diamond)$. Empty symbols are for outliers in (a) and (b). Crossed symbols are for outliers in (c).

$$
\begin{gathered}
f\left(\varepsilon_{\mathrm{r}}\right)=\frac{\left(\varepsilon_{\mathrm{r}}-1\right)}{\left(2 \varepsilon_{\mathrm{r}}+1\right)} \\
E=E_{T, 30}-25.10-14.84 f\left(\varepsilon_{\mathrm{r}}\right)-9.59 f\left(n^{2}\right)
\end{gathered}
$$

Whatever the combination of parameters - from one to six parameters - applied to the KP relationship (eqn (10)) the basicity $B$, the molecular volume $V_{\mathrm{M}}$ and the polarizability $f\left(n^{2}\right)$ are useless to describe the effect of the solvent on $a_{\mathrm{N}}$, except for

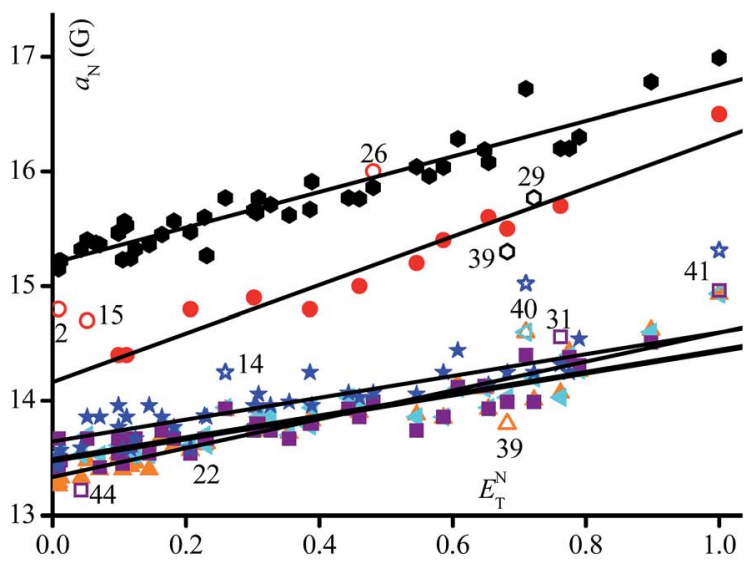

(a)

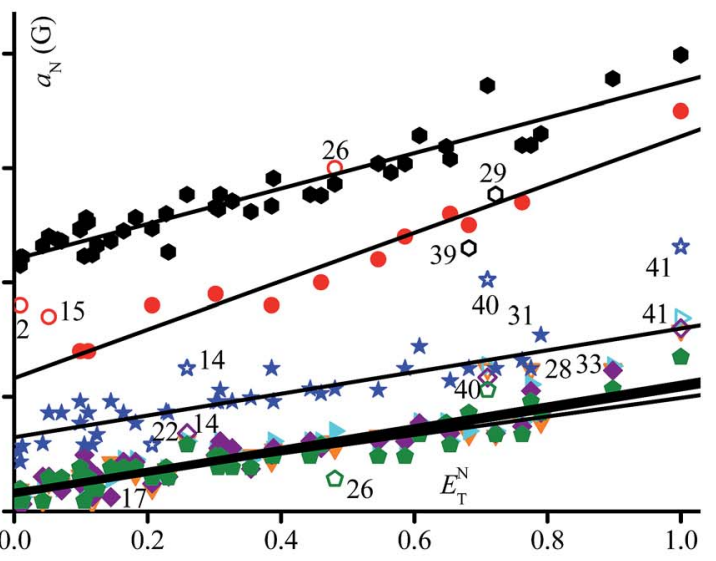

(b)

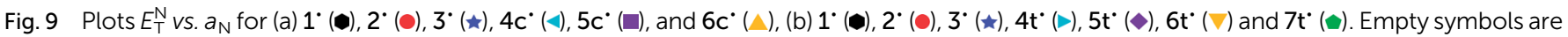
for outliers. 


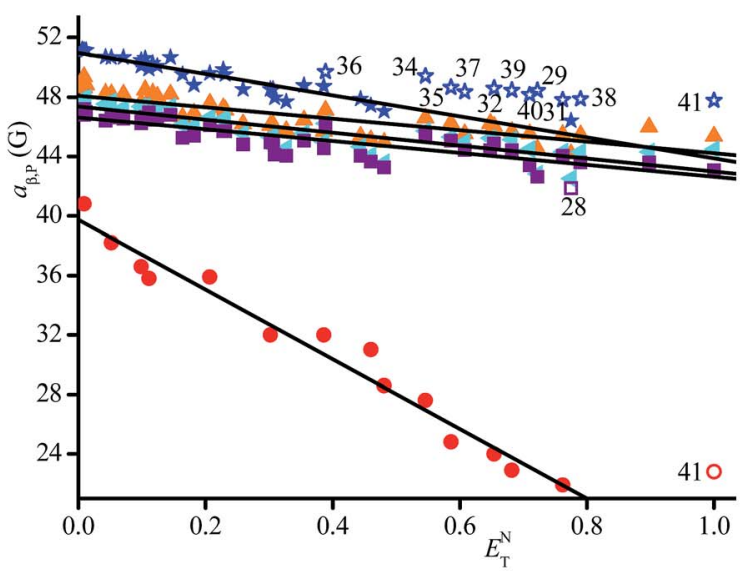

(a)

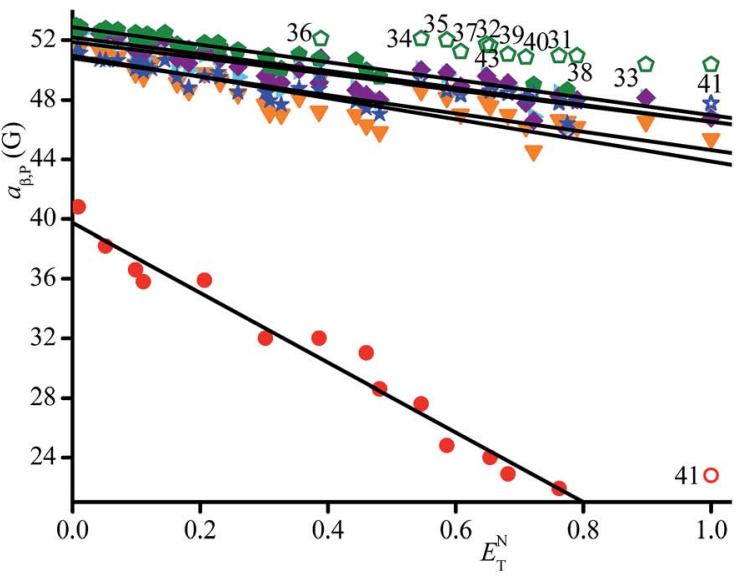

(b)

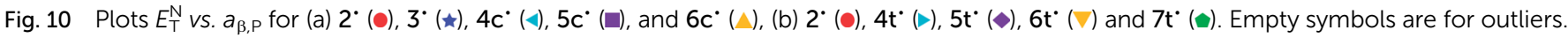

Table 2 Correlations for $a_{N} v s . E_{T}^{N}$ for $1^{*}-7 t^{*}$ in various solvents

\begin{tabular}{|c|c|c|c|c|c|c|c|c|}
\hline Eqn & Nitroxide & Slope $\alpha_{7}$ & Error $^{a}$ & $y$-Intercept & Error $^{a}$ & $R^{2 b}$ & $N^{c}$ & Outliers \\
\hline (7a) & $1^{\circ}$ & 1.55 & 8 & 15.20 & 3 & 0.90 & 44 & 29,39 \\
\hline (7b) & $2^{\circ}$ & 2.12 & 15 & 14.16 & 8 & 0.96 & 12 & $2,15,26$ \\
\hline (7d) & $4 c^{\circ}$ & 0.95 & 6 & 13.49 & 3 & 0.85 & 41 & 40,41 \\
\hline (7e) & $4 t^{\circ}$ & 0.95 & 6 & 13.17 & 2 & 0.86 & 41 & 40,41 \\
\hline (7f) & $5 c^{\circ}$ & 0.96 & 7 & 13.47 & 3 & 0.81 & 40 & $31,41,44$ \\
\hline (7i) & $6 t^{\circ}$ & 0.81 & 5 & 13.18 & 2 & 0.86 & 38 & $17,28,33,40,41$ \\
\hline$(7 \mathrm{j})$ & $7 t^{\circ}$ & 0.93 & 6 & 13.13 & 3 & 0.86 & 41 & 26,40 \\
\hline
\end{tabular}

${ }^{a}$ Error given on the last digit. ${ }^{b}$ Square of the regression coefficient. ${ }^{c}$ Number of data.

$\mathbf{1}^{*}$ for which a correlation is observed (eqn (10a)) with $E$ and $f\left(n^{2}\right)$ and not with $f\left(\varepsilon_{\mathrm{r}}\right)$. For $\mathbf{2}^{*}$, only $E$ is sufficient to describe the effect of the solvent (the occurrence of the polarizability $f\left(n^{2}\right)$ is $84 \%$ reliable, below the conventional statistical requirements (eqn (10b)) in Table 7). The solvent effect for $\mathbf{3}^{-}-\mathbf{7 t}^{*}$ is described by the acidity $E$ and the cohesive pressure $c$ (as an example see Fig. $4 \mathrm{SI} \dagger$ ). For $\mathbf{5} \mathbf{c}^{\cdot} \mathrm{MeOH}(31)$ and $\mathrm{Et}_{3} \mathrm{~N}(44)$ are outliers, for $\mathbf{5} \mathbf{t}^{*}$, chloroform (14) and i- $\mathrm{Pr}_{2} \mathrm{O}(18)$ are outliers, with no rationale at this time, and TEG (39) is outlier for $\mathbf{6 c}^{\mathbf{*}}-$ likely due to its high viscosity (Table 5).

Noteworthy, solvent effects in nitroxides $\mathbf{4}^{\cdot} \mathbf{- 6}^{\cdot}$ are also well described by the cohesive pressure $c$ and the polarizability $f\left(\varepsilon_{\mathrm{r}}\right)$ (see Table 7SI $\dagger$ ).

Whatever the combination of parameters - from one to six parameters - applied to the KP relationship (eqn (11)), the basicity $B$ and polarizability $f\left(n^{2}\right)$ are useless to describe the effects of the solvent on $a_{\beta, \mathrm{P}}$ (very poor statistical outputs). Surprisingly, the changes in $a_{\beta, \mathrm{P}}$ of $2^{\circ}$ with the solvent cannot be described by eqn (11). Interestingly, $a_{\beta, \mathrm{P}}$ for $\mathbf{4}^{\circ}-\mathbf{7 \mathbf { t } ^ { \circ }}$ are described by a 3 parameter KP relationship (Table 6$): f\left(\varepsilon_{\mathrm{r}}\right)$ (polarity), $c$ (cohesive pressure), and $V_{\mathbf{M}}$ (molar volume). Indeed, good statistical outputs are obtained with two parameters $\left(f\left(\varepsilon_{\mathrm{r}}\right)\right.$ and $\left.c\right)$ but the scattering is decreased when $V_{\mathrm{M}}$ is included (Fig. 5SI and $6 \mathrm{SI} \dagger) \cdot|\|| \mid$ At the difference of $4^{\circ}-7 \mathbf{t}^{\circ}, a_{\beta, \mathrm{P}}$ of $3^{\circ}$ are described by a two-parameter correlation: $f\left(\varepsilon_{\mathrm{r}}\right)$ and $V_{\mathrm{M}}$. Water (41) is the only outlier observed for KP relationships relying on $f\left(c, f\left(\varepsilon_{\mathrm{r}}\right)\right)$ or $f(c$, $\left.f\left(\varepsilon_{\mathrm{r}}\right), V_{\mathrm{M}}\right)$. Water is a small molecule, it might occur that its effect might not be described using conventional molecular descriptors. ${ }^{13,36,37}$ In the case of $\mathbf{6 t}^{\circ}$, no outliers are observed when $f\left(\varepsilon_{\mathrm{r}}\right)$, $c$, and $V_{\mathrm{M}}$ are used as parameters.

Solvent effects on $a_{\mathrm{N}}$ and $a_{\beta, \mathrm{P}}$ are also described by the KAT relationships (eqn (15) and (16), respectively) relying on 4-6 cybotactic parameters: ${ }^{13}$ one non specific parameter $\pi^{*}$ describing the polarity/polarizability effect, the discontinuous polarizability correction term $\delta$, the Hydrogen Bonding Acceptor (basicity) HBA property $\beta$ and the Hydrogen Bonding Donor (acidity) property $\alpha$. In some cases, cohesive pressure $c$ is included in the KAT relationship. In our case, the intrinsic volume $V_{\mathrm{X}}$, as given by McGowan, ${ }^{38}$ was also included.

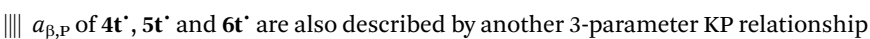
relying on the polarity $f\left(\varepsilon_{\mathrm{r}}\right)$, the acidity/electrophily $E$, and the molar volume $V_{\mathrm{M}}$, with good statistical outputs (see Table $3 \mathrm{SI} \dagger$ ). Good statistical outputs are obtained when $f\left(\varepsilon_{\mathrm{r}}\right)$ and $E$ are used but the scattering decreases when $V_{\mathrm{M}}$ is included (Fig. 4SI†). 
Table 3 Correlations for $a_{\beta, P}$ vs. $E_{T}^{N}$ for $2^{*}-7 t^{*}$ in various solvents

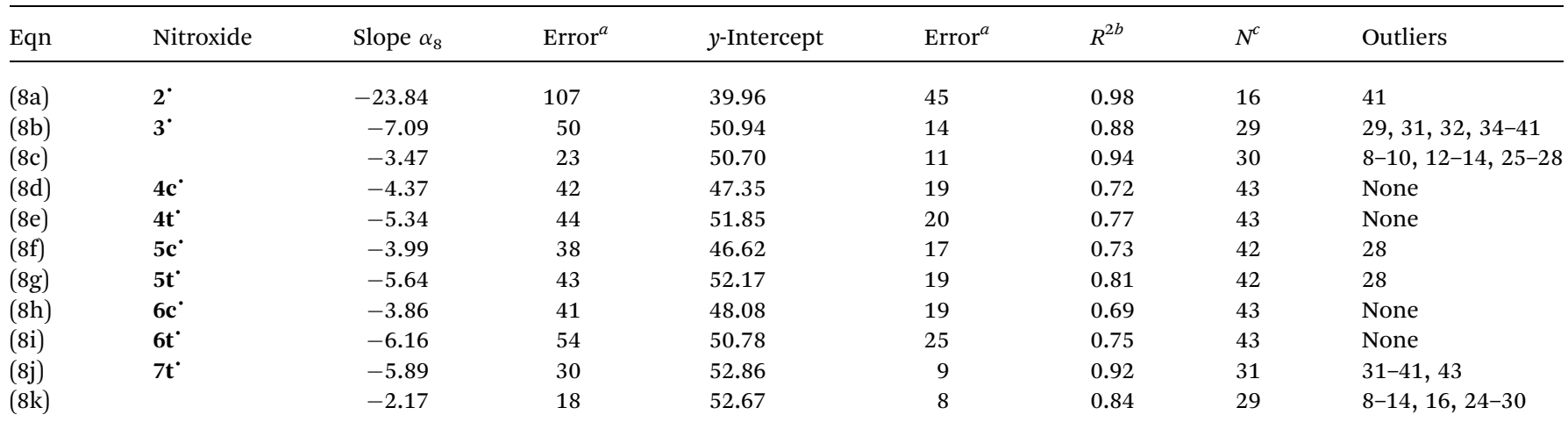

${ }^{a}$ Error given on the last digit. ${ }^{b}$ Square of the regression coefficient. ${ }^{c}$ Number of data.

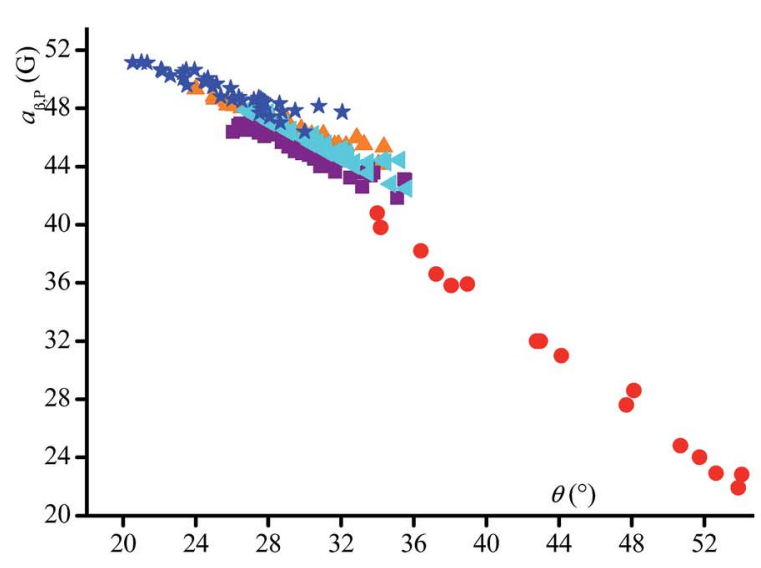

(a)

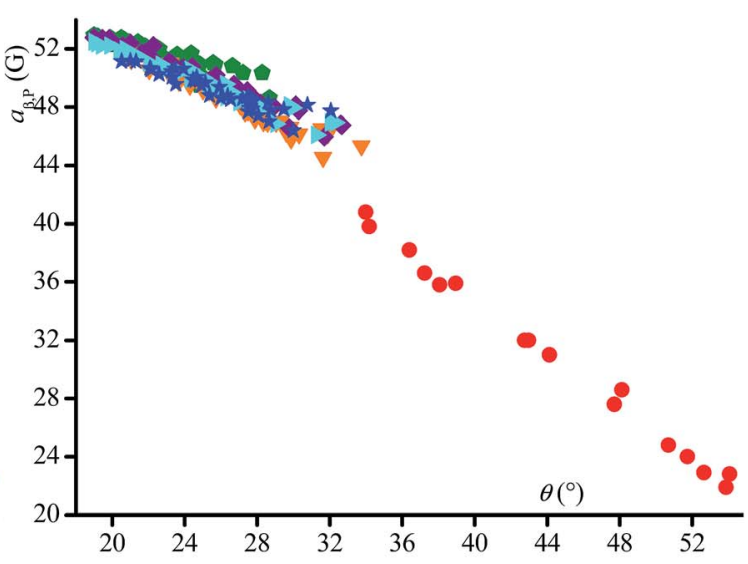

(b)

Fig. 11 Plots $\theta$ vs. $a_{\beta, P}$ for (a) $2^{*}(\bullet), 3^{*}(\star), 4 c^{*}(\triangleleft), 5 c^{*}(\square)$, and $6 c^{\circ}(\Delta),(b) 2^{*}(\bullet), 3^{*}(\star), 4 t^{*}(\triangleright), 5 t^{*}(\triangleleft), 6 t^{*}(\nabla)$ and $7^{*}(\Delta)$.

$\log a_{\mathrm{N}}=\log a_{\mathrm{N} 0}+c_{1}\left(\pi^{*}+c_{2} \delta\right)+c_{3} \alpha+c_{4} \beta+c_{5} \delta_{\mathrm{H}}^{2}+\left(c_{6} V_{\mathrm{X}}\right)$

$$
\begin{gathered}
\log a_{\beta, \mathrm{P} \beta}=\log a_{\beta, \mathrm{P} 0}+d_{1}\left(\pi^{*}+d_{2} \delta\right)+d_{3} \alpha+d_{4} \beta+d_{5} \delta_{\mathrm{H}}^{2} \\
+\left(d_{6} V_{\mathrm{X}}\right) \\
E_{\mathrm{T}}^{\mathrm{N}}=0.36 \pi^{*}+0.47 \alpha+0.01
\end{gathered}
$$

Whatever the combination of parameters - from one to six parameters - applied to the KAT relationship (eqn (15)): the HBA property $\beta$, the intrinsic molecular volume $V_{\mathrm{X}}$, and the discontinuous polarizability correction term $\delta$ are useless to describe the effects of the solvent on $a_{\mathrm{N}}$ (very poor statistical outputs). The normalized Reichardt $E_{\mathrm{T}}^{\mathrm{N}}$ encompasses three effects: polarity, polarizability, and HBD property $\alpha$ of the

\begin{tabular}{|c|c|c|c|c|c|c|c|c|c|}
\hline Nitroxide & Solvent & $a_{\beta, \operatorname{Pmax}}(\mathrm{G})$ & $a_{\mathrm{N}}(\mathrm{G})$ & $\theta_{1}^{a}\left(^{\circ}\right)$ & Solvent & $a_{\beta, \operatorname{Pmin}}(\mathrm{G})$ & $a_{\mathrm{N}}(\mathrm{G})$ & $\theta_{\max }^{b}\left({ }^{\circ}\right)$ & $\Delta \theta^{c}\left({ }^{\circ}\right)$ \\
\hline $2^{\cdot}$ & $n$-Hexane & 40.80 & 14.80 & 34 & $\mathrm{MeOH}$ & 21.90 & 16.20 & 54 & 20 \\
\hline $3^{\cdot}$ & Cyclohexane & 51.17 & 13.52 & 21 & Formamide & 46.41 & 14.25 & 32 & 11 \\
\hline $4 c^{\circ}$ & $n$-Octane & 47.94 & 13.53 & 27 & Formamide & 42.50 & 14.40 & $36^{d}$ & 9 \\
\hline $4 t^{\circ}$ & $n$-Octane & 52.48 & 13.12 & 19 & Formamide & 46.12 & 14.11 & 32 & 12 \\
\hline $5 c^{\circ}$ & $n$-Pentane & 47.18 & 13.67 & $27^{e}$ & Formamide & 41.85 & 14.38 & 36 & 10 \\
\hline $5 t^{\circ}$ & n-Octane & 52.79 & 13.06 & 19 & Formamide & 45.98 & 14.05 & 33 & 14 \\
\hline $6 c^{\circ}$ & $n$-Pentane & 49.34 & 13.26 & 24 & Formamide & 44.16 & 14.43 & 34 & 10 \\
\hline $6 t^{\circ}$ & $n$-Hexane & 51.74 & 13.19 & 21 & $\mathrm{NMF}^{f}$ & 44.56 & 13.66 & 34 & 13 \\
\hline $7 \mathbf{t}^{\circ}$ & Cyclohexane & 52.95 & 13.09 & 19 & Formamide & 48.62 & 13.96 & $29^{d}$ & 10 \\
\hline
\end{tabular}

Table $4 a_{\beta, P \max }$ and the corresponding $a_{N}, a_{\beta, P \min }$ and the corresponding $a_{N}$, dihedral angle $\theta_{1}, \theta_{\max }$ and the difference $\Delta \theta$ in their corresponding solvents for nitroxides $2^{\circ}-7 t^{\circ}$

${ }^{a} \theta_{1}$ corresponds to $\theta_{\min }$ unless otherwise mentioned. ${ }^{b}$ Given in water unless otherwise mentioned. ${ }^{c} \Delta \theta=\theta_{\text {max }}-\theta_{\text {min }}{ }^{d}$ Given in formamide. ${ }^{e}$ In $\mathrm{Et}_{3} \mathrm{~N}, \theta_{\min }=26^{\circ} .{ }^{f} \mathrm{NMF}=N$-methyl formamide. 
Table 5 Koppel-Palm linear correlations of $a_{N}$ for $1^{\circ}-7 t^{*}$

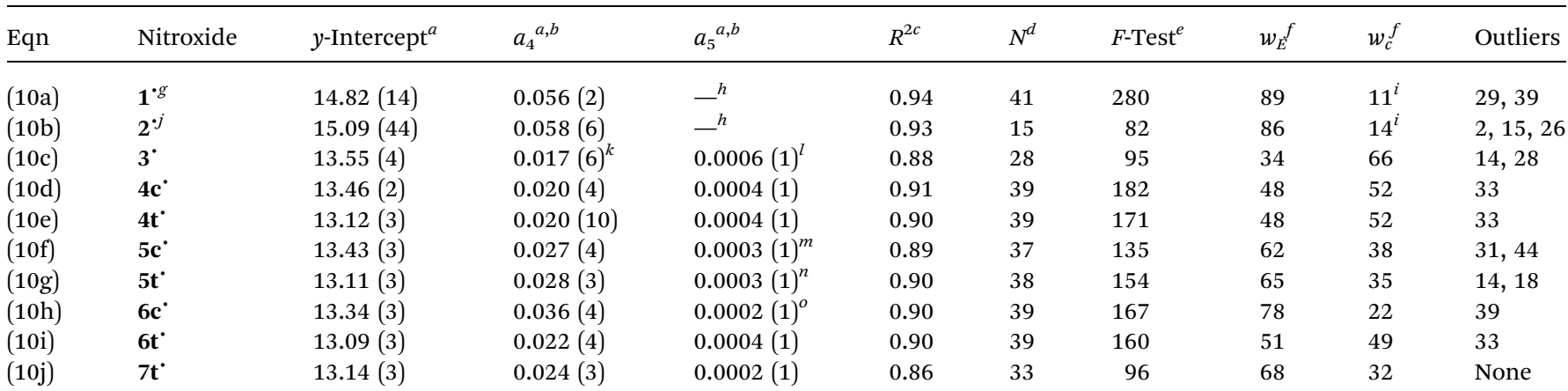

${ }^{a}$ Errors are given on the last digit in parentheses. ${ }^{b}$ Student $t$-test at $99.99 \%$ unless otherwise mentioned. ${ }^{c}$ Square of the regression coefficient.

${ }^{d}$ Number of data. ${ }^{e}$ Student-Fischer $F$-test given at $99.99 \%$ unless otherwise mentioned. ${ }^{f}$ Weight of each parameter in percent with an error of $\pm 7 \%$ as given by eqn (18) and (19). ${ }^{g}$ Polarizability was the only parameter affording reliable statistical outputs, i.e., $a_{1}=1.61(50)$ and $t=$ $99.73 \%$. ${ }^{h}$ Not included in the correlation. ${ }^{i}$ Given for $f\left(n^{2}\right) .{ }^{j} a_{1}=-2.39$ (1.59) and $t$-test at $84 \%$. Other possibilities were even worse. ${ }^{k} t=$ $98.50 \% .{ }^{l} t=99.00 \% .{ }^{m} t$-Test at $99.94 \% .{ }^{n} t$-Test at $99.90 \%$. ${ }^{o} t=99.35 \%$.

Table 6 Koppel-Palm multiparameter correlations (eqn (11)) based on the Kirkwood function of the relative permittivity $\varepsilon_{r}$, the cohesive pressure $c$ (square of the Hildebrand solubility parameter $\delta$ ), and on the molar volume $V_{M}$ for nitroxides $3^{*}-7 t^{*}$

\begin{tabular}{|c|c|c|c|c|c|c|c|c|c|c|c|c|}
\hline Eqn & & $\log a_{\beta, \mathrm{P}, 0}{ }^{a}$ & $b_{2}^{a, b}$ & $b_{5}{ }^{a, b}$ & $b_{6}{ }^{a, b}$ & $R^{2 c}$ & $F^{d}$ & $N^{e}$ & $w_{f\left(\varepsilon_{\mathrm{r}}\right)}{ }^{f}$ & $w_{c}^{f}$ & $w_{V_{\mathrm{M}}}^{f}$ & Outliers \\
\hline (11a) & $3^{\circ}$ & $50.4(7)$ & $-6.8(12)$ & ${ }^{g}$ & $0.014(4)^{h}$ & 0.79 & 62 & 35 & 60 & & 40 & 34 \\
\hline (11b) & $4 c^{\circ}$ & $47.8(7)$ & $-5.8(12)$ & $-0.0019(5)^{i}$ & $0.012(4)$ & 0.87 & 82 & 39 & 41 & 34 & 25 & 41 \\
\hline (11d) & $5 c^{\circ}$ & $47.0(7)$ & $-4.3(13)^{k}$ & $-0.0022(5)^{h}$ & $0.009(4)^{l}$ & 0.82 & 54 & 39 & 34 & 44 & 22 & 41 \\
\hline (11e) & $5 t^{\circ}$ & $52.7(7)$ & $-6.1(13)$ & $-0.0029(5)$ & $0.013(4)^{m}$ & 0.90 & 100 & 39 & 35 & 42 & 23 & 41 \\
\hline (11f) & $6 c^{\circ}$ & $48.6(7)$ & $-5.3(13)^{h}$ & $-0.0016(5)^{n}$ & $0.009(4)^{o}$ & 0.82 & 55 & 39 & 44 & 33 & 23 & 41 \\
\hline
\end{tabular}

${ }^{a}$ Errors are given on the last digit in parentheses. ${ }^{b}$ Student $t$-test of confidence given at $99.99 \%$ unless otherwise mentioned. ${ }^{c}$ Square of the regression coefficient. ${ }^{d}$ Student-Fischer $F$-test of reliability given at $99.99 \%$ confidence. ${ }^{e}$ Number of data. ${ }^{f}$ Weight of each parameter in per cent with an error of $\pm 7 \%$ as given by eqn (18) and (19). ${ }^{g}$ Not included in the correlation. ${ }^{h} t=99.90 \% .{ }^{i} t=99.98 \% .{ }^{j} t=99.00 \% .{ }^{k} t=$ 99.80\%. ${ }^{l} t=97.40 \% .{ }^{m} t=99.64 \% .{ }^{n} t=99.95 \% .{ }^{o} t=97.80 \% .{ }^{p} t=91.70 \% .{ }^{q} t=98.20 \% .{ }^{r} t=99.96 \%$.

solvent (eqn (17)). As expected from eqn (17) and correlations $a_{\mathrm{N}}=f\left(E_{\mathrm{T}}^{\mathrm{N}}\right)$ (Table 2), good correlations involving $\pi^{*}$ and $\alpha$ are obtained and they are reported in Table 7. Nevertheless, the use of a 3-parameter correlation using $c$ affords better statistical outputs (Table 7), which is observed as a decrease in the scattering (Fig. 7SI $\dagger$ ). Interestingly, the use of $c$ for the correlation of $4 \mathbf{t}^{\circ}, 5 \mathbf{t}^{\circ}$, and $6 \mathbf{t}^{\circ}$ leads to suppress the outliers observed when two parameter correlations are applied. Several outliers are observed that are different for each nitroxide, and also different according to the type of correlation applied (2(see Table 9SI $\dagger$ ) or 3-parameter correlations, except for $\mathbf{1}^{\circ}$ and $\left.2^{\circ}\right)$ and also different from those reported for $a_{\mathrm{N}}=$ $f\left(E_{\mathrm{T}}^{\mathrm{N}}\right)$ (Table 2).

Whatever the combination of parameters - from one to six parameters - applied to the KAT relationship (eqn (16)): the HBA property $\beta$ and the discontinuous polarizability correction term $\delta$ are useless to describe the effects of the solvent on $a_{\beta, \mathrm{P}}$ (very poor statistical outputs). As expected from correlations $a_{\beta, \mathrm{P}}=$ $f\left(E_{\mathrm{T}}^{\mathrm{N}}\right)$ and eqn (17), polarity/polarizability $\pi^{*}$ and HBD property $\alpha$ are required to describe $a_{\beta, \mathrm{P}}$ values. ${ }^{* * *}$ The biparameter $\left(\pi^{*}\right.$, $\alpha)$ relationships are slightly improved when the intrinsic volume $V_{\mathrm{X}}$ is included, as exemplified with $\mathbf{6 c}^{\circ}$ (Fig. 8SI $\dagger$ ). Interestingly, $a_{\beta, \mathrm{P}}$ for $3^{*}$ are well described using either $\pi^{*}$ and $\alpha$ or $\pi^{*}$ and $V_{\mathrm{X}}$ (see Table 10SI $\dagger$ ) as parameters whereas only a moderate correlation with $\pi^{*}$ and $V_{\mathrm{X}}$ is observe for $7 \mathbf{t}^{*}$ ( 7 outliers in Table 8). Acetonitrile (25), nitromethane (26), formamide (28), $\mathrm{N}$ methyl formamide (29), and water (41) are the most frequently observed outliers, with no rationale at this time.

Besides the absolute values of the coefficients of the KP and KAT relationships which describe the impact of each effect, the relative distribution given by their weight ( $w$ in \%, eqn (18) and (19)) provides information on their relative 
Table 7 Kalmet-Aboud-Taft multiparameter correlations (eqn (15)) for $a_{N}$ of nitroxides $1^{*}-7 t^{*}$ based on the polarity/polarizability parameter $\pi^{*}$, the cohesive pressure $c$, and on the Hydrogen Bonding Donor (HBD) parameter $\alpha$ of solvents

\begin{tabular}{|c|c|c|c|c|c|c|c|c|c|c|c|c|}
\hline Eqn & & $y$-Intercept ${ }^{a}$ & $c_{1}^{a, b}$ & $c_{3}^{a, b}$ & $c_{5}^{a, b}$ & $R^{2 c}$ & $F^{d}$ & $N^{e}$ & $w_{\pi^{*}}^{f}$ & $w_{\alpha}^{f}$ & $w_{c}^{f}$ & Outliers \\
\hline (15a) & $1^{\circ}$ & 15.18 (3) & $0.49(6)$ & $0.68(4)$ & $0.0002(6)^{g}$ & 0.96 & 281 & 41 & 30 & 58 & 12 & 29,39 \\
\hline (15b) & 2 & $14.00(14)$ & $1.05(20)^{h}$ & $1.13(9)$ & ${ }^{i}$ & 0.96 & 103 & 12 & & & & $2,15,26$ \\
\hline (15d) & $4 c^{\circ}$ & $13.41(3)$ & $0.29(6)$ & $0.23(5)$ & $0.0004(1)$ & 0.93 & 167 & 39 & 27 & 26 & 46 & 33 \\
\hline (15e) & $4 t^{\circ}$ & $13.07(3)$ & $0.35(6)$ & $0.34(4)$ & $0.0003(1)$ & 0.93 & 154 & 40 & 30 & 27 & 43 & None \\
\hline (15f) & $5 c^{\circ}$ & $13.34(4)$ & $0.36(6)$ & $0.35(5)$ & $0.0004(1)$ & 0.91 & 117 & 38 & 27 & 36 & 37 & 1,31 \\
\hline (15i) & $6 t^{\circ}$ & $13.07(3)$ & $0.26(7)^{k}$ & $0.38(5)$ & $0.0003(1)$ & 0.91 & 123 & 40 & 22 & 45 & 33 & None \\
\hline (15j) & $7 t^{\circ}$ & $13.09(2)$ & $0.29(5)$ & $0.25(4)$ & $0.0003(1)$ & 0.94 & 150 & 32 & 29 & 31 & 40 & 26,33 \\
\hline
\end{tabular}

${ }^{a}$ Errors are given on the last digit in parentheses. ${ }^{b}$ Student $t$-test of confidence given at $99.99 \%$ unless otherwise mentioned. ${ }^{c}$ Square of the regression coefficient. ${ }^{d}$ Student-Fischer $F$-test of reliability given at $99.99 \%$ confidence. ${ }^{e}$ Number of data. ${ }^{f}$ Weight of each parameter in percent with an error of $\pm 7 \%$ as given by eqn (18) and (19). ${ }^{g} t=99.10 \% .{ }^{h} t=99.94 \% .{ }^{i}$ Not used in the correlation. ${ }^{j} t=99.98 \% .{ }^{k} t=99.96 \%$.

Table 8 Kalmet-Aboud-Taft multiparameter correlations (eqn (16)) for $a_{\beta, P}$ of nitroxides $2^{*}-7 t^{*}$ based on the polarity/polarizability parameter $\pi^{*}$, the intrinsic volume $V_{x}$, and on the Hydrogen Bonding Donor (HBD) parameter $\alpha$ of solvents

\begin{tabular}{|c|c|c|c|c|c|c|c|c|c|c|c|c|c|c|}
\hline Eqn & & $y$-Intercept ${ }^{a}$ & $d_{1}^{a, b}$ & $d_{3}^{a, b}$ & $t^{b}$ & $d_{6}^{a, b}$ & $t$ & $R^{2 c}$ & $F^{d}$ & $N^{e}$ & $w_{\pi^{*}}^{f}$ & $w_{\alpha}^{f}$ & $w_{V_{\mathrm{x}}}^{f}$ & Outliers \\
\hline (16a) & $2 \cdot$ & $40.52(58)$ & $-9.87(93)$ & $-12.86(63)$ & 99.99 & $-g$ & $-^{f}$ & 0.98 & 297 & 14 & 34 & 66 & & 41 \\
\hline (16b) & $3^{\circ}$ & $51.00(11)$ & $-2.75(20)$ & $-0.56(18)$ & 99.55 & $-g$ & $-^{f}$ & 0.91 & 146 & 30 & 81 & 19 & & $\begin{array}{l}12,13,25,26 \\
28,31\end{array}$ \\
\hline (16c) & $4 c^{\circ}$ & $46.40(49)$ & $-2.94(37)$ & $-0.69(28)^{h}$ & 98.30 & $1.60(47)$ & 99.82 & 0.84 & 60 & 39 & 57 & 18 & 25 & 41 \\
\hline (16d) & $4 t^{\circ}$ & $51.31(38)$ & $-3.44(38)$ & $-0.77(21)^{i}$ & 99.91 & $1.15(36)$ & 99.96 & 0.91 & 117 & 38 & 63 & 19 & 18 & 28,29 \\
\hline$(16 \mathrm{e})$ & $5 c^{\circ}$ & $46.29(31)$ & $-2.45(23)$ & $-0.66(17)^{j}$ & 99.95 & $0.69(30)$ & 97.10 & 0.90 & 97 & 35 & 63 & 23 & 14 & $5,25,26,28,29$ \\
\hline (16h) & $6 t^{\circ}$ & $50.78(40)$ & $-4.26(30)$ & $-1.02(22)$ & 99.99 & $0.77(40)$ & 94.30 & 0.94 & 159 & 37 & 68 & 22 & 10 & $25,26,29$ \\
\hline (16i) & $7 t^{\circ}$ & $52.23(23)$ & $-1.89(18)$ & $\_^{g}$ & $\smile^{g}$ & $0.007(2)$ & 99.36 & 0.87 & 102 & 32 & 77 & & 23 & $\begin{array}{l}10,12,13,25, \\
26,28,29\end{array}$ \\
\hline
\end{tabular}

${ }^{a}$ Errors are given on the last digit in parenthesis. ${ }^{b}$ Student $t$-test of confidence given at $99.99 \%$ unless otherwise mentioned. ${ }^{c}$ Square of the regression coefficient. ${ }^{d}$ Student-Fischer $F$-test of reliability given at $99.99 \%$ confidence. ${ }^{e}$ Number of data. ${ }^{f}$ Weight of each parameter in

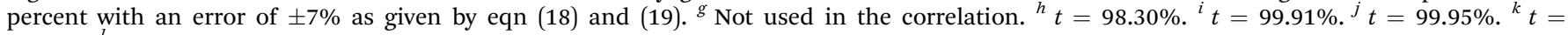
99.98\%. ${ }^{l} t=95.00 \%$.

importance..$^{39,40}$ The weight (eqn (18)) of each effect depends on each parameter $C_{i}$ - which are not on the same scale - and their respective weighted parameters $\alpha_{i}$ given in eqn (19). The latter depends on the average of each parameter and on the degree of freedom (number of data $N$ and number of parameters $p$, eqn (19)).

$$
\begin{gathered}
w=\frac{\alpha_{i} C_{i}}{\sum \alpha_{i} C_{i}} \\
\alpha_{i}=\sqrt{\frac{\sum_{i-1}^{N}\left(x_{i}-\bar{x}_{i}\right)^{2}}{N-(p-1)}}
\end{gathered}
$$

\section{Discussion}

\section{Preparation of nitroxides $4^{-}-6^{*}$}

Aziridines are analogues of epoxides, except that they are much less applied and are considered as ugly cousins. ${ }^{\mathbf{4 1}}$ Nevertheless, aziridines can readily react as epoxides do, when a strong electronwidthdrawing group is attached to the nitrogen atom. In our case, although weakly activated, aziridines turn out to be versatile key intermediates affording an easy and diastereoselective access to nitroxides $4^{\circ}-\mathbf{7 t}^{\circ}$ via the one-step addition of the azide and acetoxy groups (Scheme 5). The combination of the polar (electronwidthdrawing effect of the diethoxyphosphoryl group) and steric effects affords a selective addition of the nucleophile on the methylenic carbon. This approach is currently under development for the preparation of new nitroxides, for example those carrying thioalkyl or thioester groups.

\section{General considerations on hecs}

For historical considerations, ${ }^{9} a_{\mathrm{N}}$ of $\mathbf{1}^{\bullet}$ are commonly accepted as the benchmark values all other $a_{\mathrm{N}}$ are compared with. As displayed in Fig. 5 and Table $2 \mathrm{SI}, \dagger$ good correlations are reported $\left(R^{2}>0.85\right)$ although several outliers are observed. Hence, $a_{\mathrm{N}}$ of $2^{\circ}$ to $7 \mathbf{t}^{\circ}$ experienced the same effect as that experienced by $a_{\mathrm{N}}$ of $\mathbf{1}^{\circ}$ but to a different extent (Table $2 \mathrm{SI} \dagger$ ), as highlighted by the slopes greater than 1 for $2^{\circ}$, between 0.69 and 0.82 for $3^{\circ}-6^{\circ}$, and 0.6 for $7 \mathbf{t}^{\circ}$. Better correlations are observed when $a_{\mathrm{N}}$ of $3^{\circ}$ is used as reference (Table $3 \mathrm{SI} \dagger$ and Fig. 6). Interestingly, except 


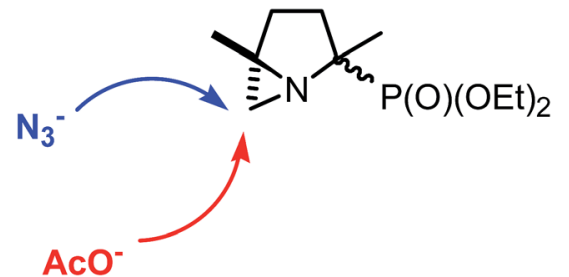

Scheme 5 Aziridine as versatile key intermediate in the preparation of $4^{\circ}-7 \mathrm{t}^{*}$.

$6 \mathbf{c}^{\circ}$ and $7 \mathbf{t}^{\circ}$ - slopes of $c a .0 .87$ and 0.66 , respectively - all phosphorylated nitroxides experienced the same solvent effect, i.e., slope $\approx 0.7-0.8$ (Table $3 \mathrm{SI} \dagger$ ).

Given by the EPR theory, ${ }^{21}$ the hyperfine coupling on position $\alpha$ is directly related to the electron density localized on the nucleus, i.e., the Fermi contact term $Q_{\mathrm{N}}$ given in eqn (20). This term depends on the shape of the localized orbital describing the odd electron. That is, for $\pi$-radicals, the SOMO is of $\mathrm{p}$-shape, i.e., a low $s$-character and then a low spin density in contact with the nucleus, and thus any increase in the $s$ character will lead to an increase in electron density and, hence, to an increase in $a_{\mathrm{N}}$.

$$
a_{\mathrm{X}}=\operatorname{cte} Q_{\mathrm{N}}
$$

In the case of nitroxides, the electron density $Q_{\mathrm{N}}$ is controlled both by the presence of electron withdrawing groups (EWG) which favours form A over form B (Fig. 12), ${ }^{7,9,10}$ that is, $Q_{N}$ decreases, $a_{\mathrm{N}}$ decreases - and by the hybridisation (pyramidalization) at the nitrogen atom, varying from $\mathrm{sp}^{3}$ to $\mathrm{sp}^{2}$ (Fig. 13), i.e., the higher the pyramidalization (form $\mathbf{C}$ ), the higher the character $s$ in the SOMO, the higher $a_{\mathrm{N}}$ and conversely.

Plots $a_{\mathrm{N}, \mathbf{1}} \cdot v s . a_{\mathrm{N}, 3^{*}-7 t}$ (Fig. 5) displayed 4 families (Table $2 \mathrm{SI} \dagger): 2^{\circ}$ with a slope greater than 1 implying higher accessibility of the nitroxyl moiety to the solvent despite the presence of EWG (vide infra), $3^{\circ}$ and $\mathbf{6 c}^{\circ}$ with a slope around $0.83, \mathbf{4} \mathbf{c}^{\circ}-\mathbf{5} \mathbf{t}^{\circ}$ and $6 \mathbf{t}^{\circ}$ exhibiting slopes close to 0.7 and $7 \mathbf{t}^{\circ}$ with a slope at 0.6 . The slopes less than 1 for the other families were due to a subtle interplay of polar effect, steric hindrance and steric strain (vide infra). To suppress the ring strain, plots $a_{\mathrm{N}, 3^{*}} \cdot v s \cdot a_{\mathrm{N}, \mathbf{4}_{-7} \cdot \mathbf{t}^{\cdot}}$ were

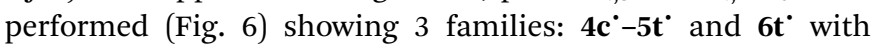
slopes between 0.7 and $0.8,6 \mathrm{c}^{\circ}$ with a slope at 0.87 , and $7 \mathrm{t}^{\circ}$ with a slope at 0.66 , highlighting again the subtle interplay of steric hindrance and polarity effect as all exhibit lower solvation effect than $3^{\circ}$, as $6 \mathbf{c}^{\circ}$ is better solvated than $6 \mathbf{t}^{\circ}$ although it exhibited the same polarity, and $7 \mathbf{t}^{\circ}$ the least efficiently solvated. Nevertheless, these results must be discussed cautionly as 4-5 solvents were considered as outliers for each nitroxide.

The Heller-McConnel relationship (1) shows that $a_{\beta, \mathrm{P}}$ is directly proportional to the electron density $\rho_{\mathrm{N}}^{\pi},{ }^{21}$ which, in turn, is expected to be linearly related to $a_{\mathrm{N}}$, implying that increasing $a_{\beta, \mathrm{P}}$ is expected with increasing $a_{\mathrm{N}}$, provided no change in the hybridization or in the mode of solvation. ${ }^{\mathbf{1 0 , 2 1}}$ Hence, a decrease in $a_{\beta, \mathrm{P}}$ is observed with increasing $a_{\mathrm{N}}$ (Table 1) leading to scattered plots between $a_{\beta, \mathrm{P}}$ and both $a_{\mathrm{N}, \mathbf{1}}$ and $a_{\mathrm{N}, 3^{*}}$ (Fig. 7). Thus, $a_{\beta, \mathrm{P}}$ of $3^{\cdot}$ was applied as reference for $4^{\bullet}$ to

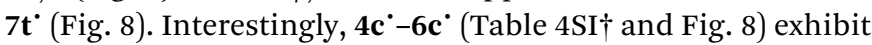

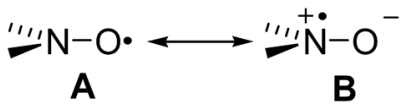

Fig. 12 Mesomeric forms of the nitroxyl moiety.

the same slope as $3^{\circ}$, meaning that the solvation of the nitroxyl moiety has the same impact on their conformations. On the other hand, $\mathbf{4} \mathbf{t}^{\mathbf{}} \mathbf{-} \mathbf{6} \mathbf{t}^{\circ}$ exhibit a higher impact whereas it is lower for $7 \mathbf{t}^{*}$ (Table $5 \mathrm{SI} \dagger^{\dagger}$ ).

\section{Correlations based on the normalized Dimroth-Reichardt constants $\boldsymbol{E}_{\mathbf{T}}^{\mathbf{N}}$}

The correlations $a_{\mathrm{N}}$ with $E_{\mathrm{T}}^{\mathrm{N}}$ or $E_{\mathrm{T}(30)}$ have been known since the work of Napier et al..$^{9}$ for $\mathbf{1}^{\circ}$ and that of Il'Yasov and coll. ${ }^{12}$ for $2^{\circ}$. As recently reported, ${ }^{\mathbf{1 7}}$ the lower $y$-intercept for $\beta$-phosphorylated nitroxides than for $\mathbf{1}^{\circ}$ is due to the presence of the strong EWG $\mathrm{P}(\mathrm{O})(\mathrm{OEt})_{2}\left(\sigma_{\mathrm{I}}=0.32\right)^{\mathbf{4 2}}$ favouring form $\mathbf{A}$ over form $\mathbf{B}$ (Fig. 12). Thus, the lower $y$-intercept for $\mathbf{4}^{\bullet}-\mathbf{7 t}^{\bullet}$ than for $3^{\bullet}$ is due to the presence of a second EWG. The lower $y$-intercept for the trans series than for the cis series is due to a more pronounced $\mathrm{sp}^{2}$ character of the $\mathrm{N}$ atom in the trans series (Fig. 13), denoting a larger strain. Recently we observed that the solvent effect (slope in eqn (7)) increased in series $\mathbf{3}^{\circ}<\mathbf{1}^{\bullet}<\mathbf{2}^{\bullet}$ due to changes both in accessibility (steric hindrance) and in sensitivity (presence of EWG) of the nitroxyl moiety. ${ }^{17}$ The polarity of nitroxides is estimated using the Hammett constant $\sigma_{\mathrm{I}}$ given as -0.06 , $0.27,0.27,0.43,0.43,0.43,0.43,0.45,0.45$, and 0.44 for $1^{\circ}-7 \mathbf{t}^{\circ}$, respectively. Hence, the nitroxides are gathered in 3 families of $\sigma_{\mathrm{I}}: \mathbf{1}^{\circ}, \mathbf{2}^{\circ}$ and $3^{\circ}$, and $\mathbf{4}^{\circ}-7 \mathbf{t}^{\circ}$. The slope increases in the series: $6 \mathbf{t}^{\circ}$ $<3^{\circ} \approx 4^{\circ} \approx 5^{\circ} \approx 7 \mathbf{t}^{\circ}<6 \mathbf{c}^{\circ}<\mathbf{1}^{\circ}<2^{\circ}$ meaning that the polarity does not play the major role. Thus, the slopes of $\mathbf{4}^{\circ}, \mathbf{5}^{\circ}$, and $7 \mathbf{t}^{\circ}$ are very close to that of $3^{\circ}$, despite the presence of a second EWG, and this implies a change in the conformation affording a better access of the nitroxyl moiety to the solvent. For $\mathbf{6 c}^{\circ}$ and $\mathbf{6 t}^{\circ}$, the presence of strongly polar azide group implies strong repelling electrostatic interaction affording conformations exhibiting either a better $\left(\mathbf{6 c}^{\circ}\right)$ or a lesser $\left(\mathbf{6 t}^{\circ}\right)$ access of the nitroxyl moiety to the solvent than in $3^{\circ}-5^{*}$, and $7 \mathbf{t}^{\circ}$. The lower slopes for $3^{-}-7 \mathbf{t}^{*}$ than for $\mathbf{1}^{\cdot}$ are in part due to higher polarity of these nitroxides than $\mathbf{1}^{\text {. }}$.

The $y$-intercepts for the plots $a_{\beta, \mathrm{P}} v s . E_{\mathrm{T}}^{\mathrm{N}}$, for $E_{\mathrm{T}}^{\mathrm{N}}=0$, correspond to the $a_{\beta, \mathrm{P}}$ values expected in $n$-pentane and $n$-hexane. Due to the significant scattering of the data, the error between expected and experimental data is around $0.5 \mathrm{G}$ (Table 3). Nevertheless, several trends emerged. The $y$-intercept (Table 3) shows that the position of the diethoxyphosphoryl groups is similar in $3^{\circ}$ and in the trans series $\left(\theta \approx 20^{\circ}\right.$, Table 4$)$ and smaller than in the cis series $\left(\theta \approx 25^{\circ}\right.$, Table 4$)$, implying a better hyperconjugation effect and, hence, larger $a_{\beta, \mathrm{P}}$ values for $3^{*}$ and the trans series.

Il'Yasov and coll. ${ }^{12}$ showed that the $a_{\beta, \mathrm{P}}$ of $2^{\circ}$ is temperature dependent, implying that the conformation of $2^{*}$ changes with the temperature, meaning that the rotation around the $\mathrm{C}-\mathrm{N}$ bond is partly free. Although the rotations around the $\mathrm{C}-\mathrm{N}$ bond are restricted in the 6-membered ring, the exchange of the 


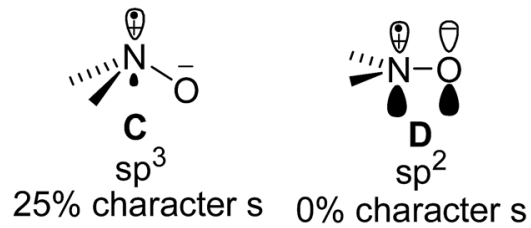

Fig. 13 Canonical forms for the hybridization at the nitrogen atom of a nitroxyl moiety and \% of character $s$ in the SOMO.

methyl groups between the equatorial and axial positions in symmetrical $1^{\circ}$ has no effect on the solvation of the nitroxyl moiety. On the other hand, eqn (1) shows that $a_{\beta, \mathrm{P}}$ depends on both the change in spin density given by $\rho_{\mathrm{N}}^{\pi}$ and the conformational changes given by $\theta$, meaning either the slope in eqn (8) increases as expected with the increasing the solvent polarity as form $\mathbf{B}$ is favoured over form $\mathbf{A}$, provided no change in conformation, i.e., $\Delta \theta \approx 0^{\circ}$ or the slope decreases implying that the conformational changes, i.e., increasing $\theta$ values, overbalance the effect of the solvent polarity. Recently, we ascribed the solvent effect to a change of conformation for a negative slope. The trends observed in Table 3 shows that the influence of solvent increases in the series as the slopes decreases: $7 \mathbf{t}^{\circ}>\mathbf{3}^{\circ} \approx$ $6 \mathrm{c}^{\circ} \approx 5 \mathrm{c}^{\circ} \approx 4 \mathrm{c}^{\circ}>4 \mathrm{t}^{\circ} \approx 5 \mathrm{t}^{\circ}>6 \mathrm{t}^{\circ}>2^{\circ}$. It comes out that the solvent has the same effect for the cis series and $3^{\circ}$. However, it is not possible to discuss quantitatively the influence of the polarity and the conformation changes on the slope.

Thus, applying eqn (9) affords some hints on the conformational changes through the variation in dihedral angle $\Delta \theta$ (Fig. 11 and Table 4). Except for $2^{\circ}$ for which $\Delta \theta=20^{\circ}$, values of $\Delta \theta$ are centered at $12^{\circ} \pm 3$. Interestingly, the distribution of the $\Delta \theta$ values is in good agreement with the slopes of eqn (4) and (5). Although such a small changes can have a clear effect on $a_{\beta, \mathrm{P}}$ $\left(\Delta a_{\beta, \mathrm{P}} \approx 2 \mathrm{G}\right.$ for $\left.\Delta \theta \approx 2^{\circ}\right)$, the change in conformation is not expected to be large enough to take into account the difference observed between the slopes.

Nevertheless, the negative slopes in eqn (8) mean that the increase in dihedral angle $\theta$ overmatches the increase in spin density $\rho_{\mathrm{N}}^{\pi}$ due to the increase in solvent polarity (vide supra). It is likely that the phosphoryl group is solvated in the same way for all nitroxides and the increase in polarity of the solvent favours form $\mathbf{F}$ (Scheme 6).

It has been noted that increasing the polarity of the solvent favours the mesomeric forms $\mathbf{B}$ and $\mathbf{F}$ of the nitroxyl and phosphoryl moieties, respectively (Fig. 12 and Scheme 6), implying that the attractive dipole-dipole interaction between the positive $\mathrm{P}$ - and the negative $\mathrm{O}$-atoms of the phosphoryl and the nitroxyl moieties, respectively, is the driving force leading to a change in the dihedral angle $\theta$ (Scheme 7 ). $+\dagger \dagger$ Such a conformation change from a non polar to a polar solvent is expected to

$\dagger \dagger$ Janzen and coll. in ref. 15 reported the same solvent effect (only benzene, methanol, and water have been investigated) for some $\beta$-phosphorylated nitroxides. They tentatively ascribed this effect to a change in conformation due to a difference in polarity of the mesomeric forms. Nevertheless, their discussion is very ambiguous and their schemes not convincing, although they might agree with our proposal. lead ultimately to the formation of a highly strained 4membered ring of the azaoxaphosphetane type (Scheme 7).

\section{Multiparameter approach. General considerations}

As mentioned above, significant scattering was observed for the plots $a_{\mathrm{N}} v s . E_{\mathrm{T}}^{\mathrm{N}}$ and $a_{\beta, \mathrm{P}} v s . E_{\mathrm{T}}^{\mathrm{N}}$. It led us to investigate the solvent effect through the Linear Solvation Energy Relationship ${ }^{\mathbf{1 3 , 4 3}}$ (LSER), as given by eqn (21), $A$ and $A_{0}$ are the values of the solvent-dependent physico-chemical properties; the polarity/ polarizability terms describe the solute/solvent dipole and induced dipole interactions: given, for example, by the Kirkwood functions $f\left(\varepsilon_{\mathrm{r}}\right.$ ) (eqn (13)), by the Lorenz-Lorentz function $f\left(n^{2}\right)$ (eqn (12)), or by $\pi^{*}$; the hydrogen bonding terms describe the interaction HBD/HBA between the solvent and the solute: given for example, by $\alpha$ and $\beta$ parameters as defined by Abraham, ${ }^{\mathbf{1 3}, 36}$ or by $E$ (electrophily/Lewis acidity) and $B$ (nucleophily/Lewis basicity) as defined by Koppel and Palm: ${ }^{\mathbf{4 4}}$ and the bulk/cavity terms (structuredness of the solvent) describe the energy needed to form cavities for the solute molecules: given, for example, by the cohesive pressure $c, V_{\mathrm{M}}$, or $V_{\mathrm{X}} \cdot^{13,36,37}$

The choice of the parameters depends on the type of correlation investigated.tt The Koppel-Palm (eqn (10) and (11)) and the Kalmet-Abboud-Taft (eqn (15) and (16)) relationships are the most popular approaches to describe the solvent effect with specific and non-specific parameters..$^{13,36,37}$

$A=A_{0}+$ polarity/polarizability terms + hydrogen bonding terms + bulk/cavity terms

Parameters $f\left(n^{2}\right), f\left(\varepsilon_{\mathrm{r}}\right), E, B, \pi^{*}, E_{\mathrm{T}}^{\mathrm{N}}, \alpha$ and $\beta$ are currently applied to describe the solvent effect on physical constants such as spectroscopic data. ${ }^{13,36,37}$ The use of the cohesive pressure $c$, the molar volume $V_{\mathbf{M}}$ and the intrinsic volume $V_{\mathrm{X}}$ is less frequent in such cases. ${ }^{13}$ Indeed, the cohesive pressure $c$ is related to the energy required to create cavities in a liquid in order to accommodate solute molecules during the process of dissolution. ${ }^{13}$ How this might play a role is not so obvious. In fact, $c$ can also be considered as a parameter describing the stiffness of structuredness of the solvent, i.e., the organization of the solvation cage. It is noticed that $c$ increases with the increasing H-bonding capacity of the solvent. The molar volume $V_{\mathrm{M}}$ is often used to take into account the effect of the size of the molecules. However, the weakness of this parameter is that the molecule is described as a sphere. ${ }^{36}$ In some cases, this issue is circumvented by using the intrinsic volume $V_{\mathrm{X}}$ as defined by McGowan, ${ }^{38}$ which takes partly into account the shape of the molecule, except that it cannot distinguish between isomers. These parameters describing the structuredness of the solvent are expected to play a role when a solute exhibits stereocenters and bulky groups.

$\$+$ Many other parameters available in the literature can be used to describe the different terms of eqn (21). Here, only the parameters used for the KP and KAT correlations are discussed. 


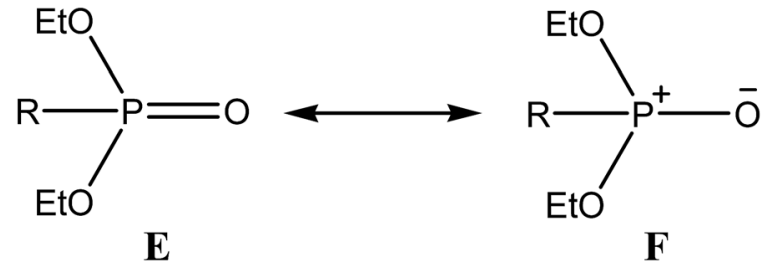

Scheme 6 Mesomeric forms for the phosphoryl group.

\section{Multiparameter approach. Analysis of $a_{N}$}

As mentioned above, significant scattering was observed for the plots $a_{\mathrm{N}}$ against $E_{\mathrm{T}}^{\mathrm{N}}$ for several nitroxides. Thus, the very popular KP and KAP relationships are applied to get deeper insight into the effects involved in the change in $a_{\mathrm{N}}{ }^{13,36,37}$ All nitroxides are well described by two-parameter KP relationships (Table 5) - $E$ and $c$ for $3^{\circ}-7 \mathbf{t}^{\circ}$ or $f\left(\varepsilon_{\mathrm{r}}\right)$ and $c$ for $\mathbf{3}^{\cdot}-\mathbf{6} \mathbf{c}^{\cdot}$ and $E$ and $f\left(n^{2}\right)$ for $\mathbf{1}^{\cdot}$ and $2 \cdot$. The use of a bi-parameter equation clearly increases the quality of the correlation (higher $R^{2}$ and good $F$-test, Table 5) and decreases the number of outliers. The absolute values of the parameters provide information on the strength of the effect while the weights (distribution of the effect for each parameter) provide insight into the importance of each effect for each nitroxide. Hence, for $\mathbf{1}^{\circ}$ and $\mathbf{2}^{\cdot}$, the use of $f\left(n^{2}\right)$ and $E$ is expected from the very good plots reported for $a_{\mathrm{N}} v s$. $E_{\mathrm{T}}(30)$ and eqn (14), as $E_{\mathrm{T}}^{\mathrm{N}}$ is described as a function of the polarizability $f\left(n^{2}\right)$, the polarity $f\left(\varepsilon_{\mathrm{r}}\right)$ and the parameter $E$.

Interestingly, taking into account the errors, $c$ does not vary significantly with the nitroxide, meaning that the structuredness of the solvent in the cybotactic region is the same around the nitroxyl moiety, and its positive value implies that the higher the structuredness, the stronger the solvent effect. However, $c$ plays a minor role $\left(w_{c}<40 \%\right)$ for $\mathbf{5} \mathbf{c}, \mathbf{t}^{\cdot}$ and $7 \mathbf{t}^{\circ}$ and it has the same weight as $E$ for $\mathbf{4 c}, \mathbf{t}^{\cdot}$ and $\mathbf{6 t}^{\circ}$. On the other hand, $c$ always plays a major role $\left(w_{c}>60 \%\right)$ when $f\left(\varepsilon_{\mathrm{r}}\right)$ is the second parameter. In fact, structuredness depends a lot on the ability of the solvent to make an H-bond network. Then, as $f\left(\varepsilon_{\mathrm{r}}\right)$ describes only the polarity effect of the solvent, the impact of $\mathrm{H}$-bonding in $a_{\mathrm{N}}$ is taken into account by $c$ affording slightly larger values when $E$ is used. Except for $\mathbf{6 c}^{\mathbf{*}}$, the values of $E$ are very close, meaning that the polar and $\mathrm{H}$-bonding properties of the solvent have the same effect on the nitroxyl moieties. This effect is enhanced for $\mathbf{6 c}^{\mathbf{*}}$, likely because the two strong EWGs are close neighbours. This is also observed with the greater influence of $E$ for $6 \mathbf{c}^{\circ}\left(w_{E}=\right.$ 78).

When $f\left(\varepsilon_{\mathrm{r}}\right)$ is used as parameter, taking into account the errors, all values are in the range $0.6-0.7$, except for $\mathbf{6 c}^{\circ}(1.08)$. As expected, all values are positive. However, their influence is lower $\left(w_{f\left(\varepsilon_{\mathrm{r}}\right)}<35 \%\right)$ than the influence of $c$. Indeed, $f\left(\varepsilon_{\mathrm{r}}\right)$ describes only the effect of the polarity of the solvent, implying that the occurrence of $\mathrm{H}$-bonding has a significant influence on the global solvent effect.

However, KP relationships do not seem to be the best approach, as the polar effect of the solvent is either described by the polarity $f\left(\varepsilon_{\mathrm{r}}\right)$ or by the Lewis acidity/electrophilic $E$, and even in two cases by the polarizability.
To circumvent this issue, the KAT relationship (eqn (15)) was applied to $\mathbf{1}^{*}-\mathbf{7 t}^{*}$, affording good 3-parameter $-\pi^{*}, \alpha$, and $c-$ correlations, except for $2^{\circ}$ and $3^{\circ}$. The scattering of the plots $E_{\mathrm{T}}^{\mathrm{N}}$ vs. $a_{\mathrm{N}}$ (Fig. 9 and Table 2 ) is significantly decreased, as highlighted by higher $R^{2}$ values, good $t$-test and $F$-test values (Table 7 and Fig. 7SI†). Noteworthily, taking into account the errors, all nitroxides experience an effect of the same strength, due to the structuredness (cohesive pressure) of the solvent, although its influence (different $w_{c}$ values) depends strikingly on the structure of the nitroxide. Interestingly, except for $\mathbf{1}^{\circ}$ and $\mathbf{6 t}^{*}$, the influence of $\alpha$ and $\pi^{*}$ is evenly shared by all nitroxides whatever the influence of the cohesive pressure. For $\mathbf{1}^{\circ}$ and $\mathbf{6 t}^{\circ}$, the major effect is the HBD properties of the solvent. As expected from the very good plot $E_{\mathrm{T}}^{\mathrm{N}} v s . a_{\mathrm{N}}$ for $\mathbf{1}^{*}$, the influence of the cohesive pressure is very weak $\left(w_{c}=12 \%\right)$. For $4^{\circ}, 5^{\circ}$, and $\mathbf{6 t}^{\circ}$, the influence of $c$ is roughly the same $\left(w_{c} \approx 35-40 \%\right)$, whereas it is significantly lower for $\mathbf{6 c}^{\cdot}\left(w_{c}=19 \%\right)$. In fact, $\mathbf{1}^{\circ}$ is a highly symmetrical molecule (the four methyl groups are equivalent, due to a fast exchange between the equatorial and axial sites). This implies that the two faces are identical, affording optimal unstrained solvation, and then the structuredness of the solvent plays hardly any role. In the case of $2^{\circ}$, the loss of symmetry ( 5 methyl groups and a phosphoryl group) is balanced by the free $\mathrm{C}-\mathrm{N}$ bond rotation, affording an optimized access to the nitroxyl moiety for efficient solvation, and again the structuredness of the solvent plays hardly any role. Surprisingly, the loss of symmetry in $3^{\circ}$ is not significant enough to induce a significant effect of the structuredness of the solvent. For $\mathbf{4}^{\mathbf{4}}, \mathbf{5}^{\mathbf{}}, \mathbf{6 t}^{\mathbf{*}}$ and $\mathbf{7 \mathbf { t } ^ { \circ }}$, the influence of $c$ is moderate, meaning that the substituents around the nitroxyl moiety hamper its solvation, whereas the mobility of the ring combined to the structuredness affords a good solvation, hence implying a moderate effect of the structuredness. For $\mathbf{6} \mathbf{c}^{\mathbf{2}}$, the repelling effect between the azido group and the phosphoryl group in cis relationship is so strong that only one conformation provides the best minimization of the repelling effect, allowing the solvent access to the nitroxyl moiety, and hence leading to a weak influence of the structuredness of the solvent. In our case, the effect of parameters $\pi^{*}$ and $\alpha$ affords very similar results, i.e., the stabilization of the zwitterionic form $\mathbf{B}$, and the discussion will only be provided for $\alpha$, except for a few cases. The highest HBD effects are reported for $\mathbf{1}^{\circ}$ and $\mathbf{2}^{*}\left(\right.$ larger $w_{\alpha}$ ). For $\mathbf{4}^{*}, \mathbf{5}^{*}, \mathbf{6}^{\circ}$ and $7 \mathbf{t}^{\circ}$, the same HBD effect is observed. The HBD effect involves a hydrogen bond between the protic solvent and the nitroxyl moiety, and as a consequence, the stronger the interaction, the more favoured form B, the higher $a_{\mathrm{N}}$.

The polarity/polarizability and hydrogen bonding effects strongly favour (positive sign for the coefficients) form $\mathbf{B}\left(\mathrm{N}^{+}{ }_{-}\right.$ $\mathrm{O}^{-}$moiety), leading to an increase in $a_{\mathrm{N}}$ with increasing solvent properties. These effects are strengthened by the cohesive pressure $c$ (positive sign for the coefficient) which is used to describe the structuredness of the solvent, i.e., higher organization or stronger solvent-solvent interactions in the cybotactic region will strengthen polarity/polarizability and H-bonding effects. Consequently, the weight of form $\mathbf{H}$ will be increased. 


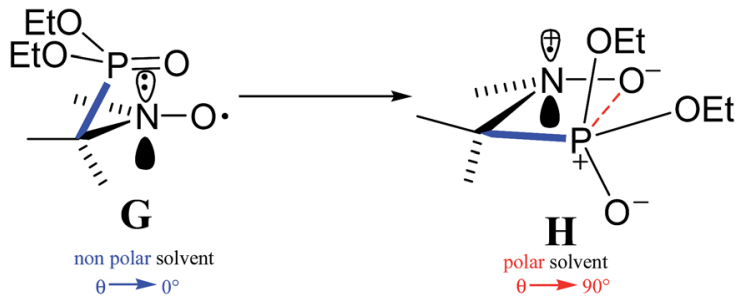

Scheme 7 Conformation change by rotation around the $\mathrm{C}-\mathrm{N}$ bond from a non polar solvent to a polar solvent.

\section{Multiparameter approach. Analysis of $\boldsymbol{a}_{\beta, \mathbf{P}}$}

As mentioned above, significant scattering was observed for the plots $a_{\beta, \mathrm{P}}$ against $E_{\mathrm{T}}^{\mathrm{N}}$ for several nitroxides. Moreover, for $3^{\circ}$ and $7 \mathbf{t}^{\circ}$, two correlations $a_{\beta, \mathrm{P}} v s$. $E_{\mathrm{T}}^{\mathrm{N}}$ were possible, providing at least 10 solvent were excluded. Then, the very popular KP and KAP relationships were applied to get deeper insight into the effects involved in the change in $a_{\beta, \mathrm{P}}$. In contrast to the correlation with $a_{\mathrm{N}}$, KAT and KP approaches are less general. Indeed, the KAT relationship (eqn (16)) is able to describe the solvent effect for $2^{*}-7 \mathbf{t}^{\mathbf{*}}$, although this cannot be done with the same set of parameters.

Surprisingly, KP relationships cannot describe the solvent effect for $2^{*}$, whatever the combination of parameters. Except for $3^{*}$, for which only $f\left(\varepsilon_{\mathrm{r}}\right)$ and $V_{\mathrm{M}}$ are required, the solvent effect is described by KP relationships using $f\left(\varepsilon_{\mathrm{r}}\right.$ ) and $c$ (see Table $3 \mathrm{SI} \dagger$ ), and the correlations are significantly improved when the size of the solvent molecule $V_{\mathrm{M}}$ is included. However, for the trans series, except for $7 \mathbf{t}^{\circ}$, the cohesive pressure $c$ can be replaced by the parameter $E$ (see Table $3 \mathrm{SI} \dagger$ ). Consequently, $E$ and $c$ likely describe the same effect: the ability of the first layer of the solvent molecules to develop stabilizing $\mathrm{H}$-bonds with the nitroxyl moiety.

Interestingly, coefficients of $f\left(\varepsilon_{\mathrm{r}}\right), E$, and $c$ are negative, implying that $a_{\beta, \mathrm{P}}$ values decrease with increasing properties. In fact, increasing $f\left(\varepsilon_{\mathrm{r}}\right), E$, and $c$ leads to favour the zwitterionic forms of the $\mathrm{N}^{-} \mathrm{O}^{\cdot}$ (form $\mathbf{B}$ ) and $\mathrm{P}=\mathrm{O}$ (form $\mathbf{F}$ ) moieties, and to favour the interaction between $\mathrm{N}^{+}-\mathrm{O}^{-} \cdots \mathrm{P}^{+}-\mathrm{O}^{-}$moieties (form H) as described in Scheme 7, which, in turn, involved an increase in the dihedral angle $\theta$ affording a decrease in $a_{\beta, \mathrm{P}}$.

On the other hand, the coefficient of the size of the solvent molecule $V_{\mathrm{M}}$ is positive, meaning that $a_{\beta, \mathrm{P}}$ increase with the size of the solvent molecule. That is, the bulkier the solvent is, more hampered the $\mathrm{PC}-\mathrm{N}$ bond rotation is, and the less favoured form $\mathbf{H}$ is. Taking into account the errors, the impact of $V_{\mathbf{M}}$ is the same for all nitroxides and its influence is minor $\left(w_{V_{\mathrm{M}}}<\right.$ $25 \%)$ on the whole solvent effect. Taking into account the errors, except for $\mathbf{6 t}^{\circ}$, the impacts of $f\left(\varepsilon_{\mathrm{r}}\right)$ and $c$ are the same for $\mathbf{4}^{\circ}-\mathbf{6} \mathbf{c}^{\cdot}$ and their influence is moderate $\left(33 \%<w_{c}\right.$ and $w_{f\left(\varepsilon_{\mathrm{r}}\right)}<$ $44 \%$ ) on the global solvent effect. Similar comments hold for the relationships involving $f\left(\varepsilon_{\mathrm{r}}\right)$ and $E$. Interestingly, $\mathbf{6 t}^{\circ}$, which carries two strong EWGs in trans relationship, exhibits the largest and the smallest coefficients for $f\left(\varepsilon_{\mathrm{r}}\right)$ and $c$, respectively, implying a major influence of $f\left(\varepsilon_{\mathrm{r}}\right)\left(w_{f\left(\varepsilon_{\mathrm{r}}\right)}=56 \%\right)$ over $c\left(w_{c}=\right.$ $19 \%)$ and $V_{\mathrm{M}}\left(w_{V_{\mathrm{M}}}=25 \%\right)$.
Unlike the KP relationship, KAT relationships are able to describe the solvent effect on $a_{\beta, P}$ for all nitroxides although this approach is marred by the number of outliers, i.e., 6-10 for $3^{\circ}, 5$ for $\mathbf{5}^{\mathbf{c}}, 3$ for $\mathbf{6 t}^{\circ}$, and 7 for $7 \mathbf{t}^{\circ}$. Except for $7 \mathbf{t}^{\circ}$, for which parameters $\pi^{*}$ and $V_{\mathrm{X}}$ are used, the solvent effect for all other nitroxides is described using $\pi^{*}$ and $\alpha$ as parameters and the correlations are significantly improved - either better statistical outputs or fewer outliers - by including the size and the shape of the solvent molecule $V_{\mathrm{X}}$ as third parameter. Interestingly, the coefficients of $\pi^{*}$ and $\alpha$ are negative, meaning that $a_{\beta, \mathrm{P}}$ decrease with increasing polarity/polarizability and the $\mathrm{H}$-bond donor properties of the solvent whereas the positive coefficient for $V_{\mathrm{X}}$ means that $a_{\beta, P}$ increase with the bulkiness of the solvent molecule. This is in nice agreement with the observation made using KP relationships and the comments reported above hold.

Taking into account the errors, the impact of $V_{\mathrm{X}}$ is roughly the same for $4^{\cdot}-6^{\circ}$ and its influence is minor $\left(w_{V_{\mathrm{X}}}<25 \%\right)$ on the global solvent effect. Taking into account the errors, the impact of $\pi^{*}$ has a major influence $\left(w_{\pi^{*}}>57 \%\right)$ for $4^{*}-7 \mathbf{t}^{*}$. Taking into account the errors, the impact of $\alpha$ is roughly $\left(w_{\alpha} \approx 17 \% \pm 6\right)$ the same for $\mathbf{4}^{\cdot}, \mathbf{5}^{\circ}$, and $\mathbf{6 t}^{\circ}$, slightly lower for $\mathbf{6 c}^{\circ}$ and its influence is very similar to that $V_{\mathrm{X}}$.

As mentioned above, the solvent effect in $2^{\circ}$ and $3^{\circ}$ is nicely described using $\pi^{*}$ and $\alpha$. As expected, their coefficients are negative. The impact of $\pi^{*}$ and $\alpha$ on $a_{\beta, \mathrm{P}}$ is clearly stronger in $2^{\circ}$ than in $3^{\circ}$, in nice agreement with $E_{\mathrm{T}}^{\mathrm{N}}$ trends. However, the weight influence of each parameter is sharply contrasted, that is, the HBD property $\alpha$ is the major effect $\left(w_{\alpha}=66 \%\right)$ in $2^{\circ}$ whereas the effect of $\pi^{*}$ is the major one $\left(w_{\pi^{*}}=81 \%\right)$ in $3^{\circ}$. Thus, it seems that less restricted rotations and likely less restricted $\mathrm{C}-\mathrm{N}$ bond rotations, provided conformations favouring the occurrence of $\mathrm{H}$-bonds in $2^{\circ}$ at the difference of the 5 -membered ring nitroxide $3^{\circ}$ in which bond rotations are dramatically restricted. The coefficients obtained for $\pi^{*}$ and $\alpha$ given by bi-parametric correlations for $4^{\circ}-6^{\circ}$ are very similar to those for $3^{*}$, meaning that the same effects are involved to a very close extent. Although different parameters are used for $\mathbf{7 t}^{\mathbf{}}$, coefficient of $\pi^{*}$ and $V_{\mathrm{X}}$ are very similar to those of $3^{*}$ given by eqn (16r) (Table 10SI $\dagger$ ), meaning that the same effects are again involved.

It stems from the comparing of KAT and KP relationships that the polarity $\left(\pi^{*}\right.$ and $\left.f\left(\varepsilon_{\mathrm{r}}\right)\right)$ and the size of the solvent molecules $\left(V_{\mathrm{X}}\right.$ and $\left.V_{\mathrm{M}}\right)$ are the main effects, which are antagonist effects, ruling the change in $a_{\beta, \mathrm{P}}$. The effect of $\alpha$ and of $c$ is less obvious, as it does not apply to all nitroxides in the same series. Nevertheless, it seems strongly linked to the stiffness of the structuredness of the solvation cage around the nitroxyl moiety and maybe also around the phosphoryl group.

Although it has a negative coefficient, the polarity/ polarizability effect plays a role that is the same for $a_{\beta, \mathrm{P}}$ as for $a_{\mathrm{N}}$, that is, increasing solvent polarity favours both form $\mathbf{B}$ and form $\mathbf{F}$, implying stronger $\mathrm{N}^{+\cdot}-\mathrm{O}^{-} \rightarrow \mathrm{P}^{+}-\mathrm{O}^{-}$interaction and, hence, a more stabilized form $\mathbf{H}$. Amazingly, $\alpha$ and $c$ do not apply to all nitroxides and can sometimes be interchanged, meaning that they do not describe their conventional effects. They both probably describe the organization of the solvent molecules around the $\mathrm{N}-\mathrm{O}^{\circ}$ and $\mathrm{P}=\mathrm{O}$ moieties in the cybotactic 
region, meaning that the higher the structuredness (negative coefficients), the stronger the $\mathrm{N}^{+}{ }^{-} \mathrm{O}^{-} \rightarrow \mathrm{P}^{+}-\mathrm{O}^{-}$interaction. On the other hand, as $4^{\circ}-6^{\circ}$ exhibit strong asymmetry around the nitroxyl moiety, the size of the solvent ( $V_{\mathrm{M}}$ of $\left.V_{\mathrm{X}}\right)$ plays an antagonist role (positive coefficient) to the polarity effect and the structuredness of the solvent.

\section{Conclusions}

This survey of the solvent effect on new $\beta$-phosphorylated nitroxides $3^{\circ}-7 \mathbf{t}^{*}$ unveils an unexpected entanglement of effects, different for $a_{\mathrm{N}}$ and $a_{\beta, \mathrm{P}}$, due to the various properties of the solvents. For all nitroxides, $a_{\mathrm{N}}$ values are affected by the polarity/polarizability $\left(\pi^{*}\right)$, H-bonding $(\alpha)$, and stiffness of the structuredness (cohesive pressure $c$ ) of the solvents. On the other hand, the impact and the occurrence of each effect are less obvious for $a_{\mathrm{P}, \beta}$ than for $a_{\mathrm{N}}$. For example, for $2^{\cdot}$ and $3^{\circ}$, only $\pi^{*}$ and $\alpha$ are observed whereas for the cyclic nitroxides $\pi^{*}, \alpha, c, V_{\mathbf{M}}$ and $V_{\mathrm{X}}$ are observed. The positive signs for $\pi^{*}, \alpha$, and $c$ mean that $a_{\mathrm{N}}$ values increase with these solvent properties. On the other hand, the negative values for $\pi^{*}, \alpha$ and $c$ mean that $a_{\beta, \mathrm{P}}$ values decrease with these solvent properties, whereas an antagonist effect is observed with $V_{\mathrm{X}}$. The anti-correlation between $a_{\beta, \mathrm{P}}$ and $a_{\mathrm{N}}$ is ascribed to the $\mathrm{N}^{+} \cdot \mathrm{O}^{-} \rightarrow \mathrm{P}^{+}-\mathrm{O}^{-}$interaction whose the maximization is the driving force of the system. As nitroxides $3^{\circ}-7 \mathbf{t}^{\cdot}$ exhibit changes in $a_{\mathrm{P} \beta}$ with the solvent, one possible application of this observation will be the titration of water in organic solvents.

\section{Experimental section}

All solvents and reactants were purchased from Aldrich and

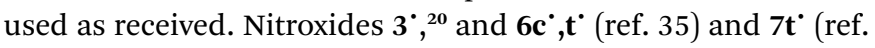
$35)$ were prepared according to the literature. Nitroxides $4 \mathbf{c}^{\circ}, \mathbf{t}^{\mathbf{*}}$,

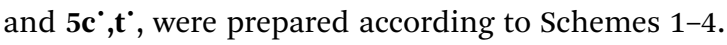

Samples were prepared at $0.5 \mathrm{mM}$ nitroxide concentration in non-degassed solvents. Experiments were performed indifferently on Elexsys, EMX or ER 100D Bruker machines (a difference smaller than $0.1 \mathrm{G}$ was noticed). EPR spectra were recorded, the parameters being a gain of $2 \times 10^{5}$ (72 dB for Elexsys), a modulation amplitude of $1.0 \mathrm{G}$, a sweep width of $150 \mathrm{G}$, a sweep time of $21 \mathrm{~s}$, and a power of $20 \mathrm{~mW}$.

\section{Acknowledgements}

The authors thank Aix-Marseille University, University of Bordeaux 2, and CNRS for financial support. ANR was granted for funding this project (grants SonRadIs ANR-11-JS07-002-01 and NITROMRI ANR-09-BLA-0017-01). LB is thankful to ANR for the Ph.D. fellowship (grant SonRadIs). The work was supported by the Russian Science Foundation (grant 15-13-20020).

\section{Notes and references}

1 G. Likhtenshtein, J. Yamauchi, S. Nakatsuji, A. I. Smirnov and R. Tamura, Nitroxides: Applications in Chemistry,
Biomedicine, and Materials Science, Wiley-VCH, 2008, and references therein.

2 Stable Radicals: Fundamentals and Applied Aspects of OddElectron Compounds, ed. R. Hicks, Wiley, Hoboken, 2010, pp. 173-229, and references therein.

3 I. A. Kirilyuk, A. A. Bobko, V. V. Khramtsov and I. A. Grigor'ev, Org. Biomol. Chem., 2005, 3, 1269-1274.

4 V. Belle, S. Rouger, S. Costanzo, A. Longhi and A. Fournel, Assessing Structures and Conformations of Intrinsically Disordered Proteins, ed. V. N. Uversky, Wiley, Hoboken, 2009, and references cited therein.

5 P. Mellet, P. Massot, G. Madelin, S. R. A. Marque, E. Harte, J.-M. Franconi and E. Thiaudière, PLoS One, 2009, 4, e5244.

6 P. Massot, E. Parzy, L. Pourtau, P. Mellet, S. Marque, J.-M. Franconi and E. Thiaudière, Contrast Media Mol. Imaging, 2012, 7, 45-50.

7 H. Karoui, F. le Moigne, O. Ouari and P. Tordo, Stable Radicals: Fundamentals and Applied Aspects of Odd-Electron Compounds, ed. R. Hicks, John Wiley \& Sons, 2010, pp. 173-229.

8 V. Ovcharenko, Stable Radicals: Fundamentals and Applied Aspects of Odd-Electron Compounds, ed. R. Hicks, John Wiley \& Sons, 2010, pp. 461-506.

9 B. Knauer and J. J. Napier, J. Am. Chem. Soc., 1976, 98, 43954400.

10 E. G. Janzen, G. A. Coulter, U. M. Oehler and J. P. Bergsma, Can. J. Chem., 1982, 60, 2725-2733.

11 C.-H. Deng, C.-J. Guan, M.-H. Shen and C.-X. Zhao, J. Fluorine Chem., 2002, 116, 109-115.

12 A. S. Mukhtarov, A. V. Il'Yasov, Y. A. Levin, I. P. Gozman, M. S. Skorobogatova and E. I. Zoroatskaya, Theor. Exp. Chem., 1976, 12, 656-660; Teor. Eksp. Khim., 1976, 12, 831836.

13 C. Reichardt and T. Welton, Solvent and Solvent Effect in Organic Chemistry, Wiley-VCH, Weinheim, 4th edn, 2011.

14 C. Reichardt, Chem. Rev., 1994, 94, 2319-2358.

15 D. L. Haire, E. G. Janzen, G. Chen, V. J. Robinson and I. Hrvoic, Magn. Reson. Chem., 1999, 37, 251-258.

16 S. Marque, C. Le Mercier, P. Tordo and H. Fischer, Macromolecules, 2000, 33(12), 4403-4410.

17 G. Audran, L. Bosco, P. Brémond, T. Butscher and S. R. A. Marque, Appl. Magn. Reson., 2015, 45(12), 1333-1342.

18 G. Audran, L. Bosco, P. Brémond, T. Butscher and S. R. A. Marque, Org. Biomol. Chem., 2016, DOI: 10.1039/ c5ob02316e.

19 G. Audran, L. Bosco, P. Brémond, T. Butscher, J.-M. Franconi, S. R. A. Marque, P. Mellet, E. Parzy, M. Santelli and E. Thiaudière, Org. Biomol. Chem., 2015, 13, 11393-11400.

20 F. le Moigne, A. Mercier and P. Tordo, Tetrahedron Lett., 1991, 32, 3841-3844.

21 F. Gerson and W. Huber, Electron Spin Resonance Spectroscopy of Organic Radicals, Wiley-VCH, Weinheim, 2003.

22 S. Acerbis, D. Bertin, B. Boutevin, D. Gigmes, P. LacroixDesmazes, C. Le Mercier, J.-F. Lutz, S. R. A. Marque, D. Siri and P. Tordo, Helv. Chim. Acta, 2006, 89(10), 2119-2132. 
23 C. Mathieu, A. Mercier, D. Witt, L. Dembkowski and P. Tordo, Free Radical Biol. Med., 1997, 22, 802-806.

24 C. Ricci, S. Marque, F. Belin, J.-C. Bouteiller, R. Lauricella, B. Tuccio, V. Cerri and P. Tordo, J. Chem. Soc., Perkin Trans. 2, 1997, 2513-2518.

25 A. Alberti, Nitroxides radicals and polynitroxides in LandoltBörnstein, New Series II/26D, ed. H. Fischer, SpringerVerlag, Heidelberg, 2005, pp. 7-537, and references therein.

26 J.-L. Clément, B. C. Gilbert, W. F. Ho, D. N. Jackson, M. S. Newton, S. Silvester, G. S. Timmins, P. Tordo and A. C. Whitwood, J. Chem. Soc., Perkin Trans. 2, 1998, 17151717.

27 F. Fréjaville, H. Karoui, B. Tuccio, F. Le Moigne, M. Culcasi, S. Pietri, R. Lauricella and P. Tordo, J. Med. Chem., 1995, 38, 258-265.

28 P. Stipa, J.-P. Finet, F. le Moigne and P. Tordo, J. Org. Chem., 1993, 58, 4465-4468.

29 L. Dembkowski, J.-P. Finet, C. Fréjaville, F. le Moigne, R. Maurin, A. Mercier, P. Pages, P. Stipa and P. Tordo, Free Radical Res., 1993, 19, S23-S32.

30 D. Gigmes and S. R. A. Marque, Nitroxide Mediated Polymerization and its Applications Encyclopedia of Radicals in Chemistry, Biology, and Materials, ed. C. Chatgilialoglu and A. Studer, Wiley, Chichester, U.K., 2012, pp. 1813-1850.

31 D. Bertin, D. Gigmes, S. R. A. Marque and P. Tordo, Chem. Soc. Rev., 2011, 40, 2189-2198.

32 E. G. Bagryanskaya, E. G. Krumkacheva, M. V. Fedin and S. R. A. Marque, Methods Enzymol., 2015, 563, 365-396.
33 G. Audran, L. Bosco, P. Brémond, J.-M. Franconi, N. Koonjoo, S. R. A. Marque, P. Massot, P. Mellet, E. Parzy and E. Thiaudière, Angew. Chem., Int. Ed., 2015, 54(45), 13379-13384.

34 D. Benoit, V. Chaplinski, R. Braslau and C. J. Hawker, J. Am. Chem. Soc., 1999, 121, 3904-3920.

35 N. le Breton, M. Martinho, K. Kabitaev, J. Topin, E. Mileo, D. Blocquel, J. Habchi, S. Longhi, A. Rockenbauer, J. Golebiowski, B. Guigliarelli, S. R. A. Marque and V. Belle, Phys. Chem. Chem. Phys., 2014, 16, 4202-4209.

36 Y. Marcus, The Properties of Solvents, Wiley, Chichester, 1998, vol. 4.

37 G. E. Zaikov, R. G. Makitra, G. G. Midyana and L. I. Bazylyak, Influence of the Solvent on Some Radical Reaction Chemistry Research and Applications Series, Nova Science Publishers Inc., New York, 2010.

38 J. C. McGowan, J. Appl. Chem. Biotechnol., 1978, 28, 599.

39 D. Bertin, D. Gigmes, S. R. A. Marque and P. Tordo, Macromolecules, 2005, 38(7), 2638-2650.

40 J. Shorter, Correlation Analysis of Organic Reactivity, J. Wiley \& Sons, New York, 1982, pp. 73-126.

41 J. B. Sweeney, Chem. Soc. Rev., 2002, 31, 247-258.

42 M. Charton, Prog. Phys. Org. Chem., 1981, 13, 119-251.

43 A. R. Katritzky, D. C. Fara, H. F. Yang, K. Tamm, T. Tamm and M. Karelson, Chem. Rev., 2004, 104, 175-198.

44 I. A. Koppel and V. A. Palm, The Influence of the Solvent on Organic Reactivity, in Advances in Linear Free Energy Relationships, ed. N. B. Chapman and J. Shorter, Plenum Press, London, New York, 1972, ch. 5, p. 203. 